This is the author's manuscript for publication. The publisher-formatted version may be available through the publisher's web site or your institution's library.

\title{
Short-term oral atrazine exposure alters the plasma metabolome of male C57BL/6 mice and disrupts $\alpha$-linolenate, tryptophan, tyrosine and other major metabolic pathways
}

Zhoumeng Lin, James R. Roede, Chunla He, Dean P. Jones, Nikolay M. Filipov

\section{How to cite this manuscript}

If you make reference to this version of the manuscript, use the following information:

Lin, Z., Roede, J. R., He, C., Jones, D. P., \& Filipov, N. M. (2014). Short-term oral atrazine exposure alters the plasma metabolome of male C57BL/6 mice and disrupts alinolenate, tryptophan, tyrosine and other major metabolic pathways. Retrieved from http://krex.ksu.edu

\section{Published Version Information}

Citation: Lin, Z., Roede, J. R., He, C., Jones, D. P., \& Filipov, N. M. (2014). Short-term oral atrazine exposure alters the plasma metabolome of male C57BL/6 mice and disrupts $\alpha$-linolenate, tryptophan, tyrosine and other major metabolic pathways. Toxicology, 326, 130-141.

Copyright: @ 2014 Elsevier Ireland Ltd.

Digital Object Identifier (DOI): doi:10.1016/j.tox.2014.11.001

Publisher's Link:

http://www.sciencedirect.com/science/article/pii/S0300483X14002133\#

This item was retrieved from the K-State Research Exchange (K-REx), the institutional repository of Kansas State University. K-REx is available at http://krex.ksu.edu 
Short-term oral atrazine exposure alters the plasma metabolome of male C57BL/6 mice and disrupts $\alpha$-linolenate, tryptophan, tyrosine and other major metabolic pathways Zhoumeng Lin ${ }^{a, b, 1}$, James R. Roede ${ }^{c, 2}$, Chunla He ${ }^{d}$, Dean P. Jones ${ }^{c}$, Nikolay M. Filipov ${ }^{a, b, \star}$

${ }^{a}$ Department of Physiology and Pharmacology, College of Veterinary Medicine, University of Georgia, Athens, GA 30602, USA; ' Interdisciplinary Toxicology Program, University of Georgia, Athens, GA 30602, USA; ' Division of Pulmonary, Allergy and Critical Care Medicine, Department of Medicine, Emory University, Atlanta, GA 30322, USA; ${ }^{d}$ Department of Epidemiology and Biostatistics, College of Public Health, University of Georgia, Athens, GA 30602, USA

Zhoumeng Lin: zhoumeng@ksu.edu; James R. Roede: James.Roede@ucdenver.edu;

Chunla He: willahe@uga.edu; Dean P. Jones: dpjones@emory.edu;

Nikolay M. Filipov: filipov@uga.edu

* Corresponding author: Department of Physiology and Pharmacology, University of Georgia, 501 D. W. Brooks Dr., Athens, GA 30602, USA. Tel.: +1-706-542-3014; fax: +1-706-542-3015. E-mail address: filipov@uga.edu

${ }^{1}$ Present address: Institute of Computational Comparative Medicine and The Department of Anatomy and Physiology, Kansas State University, Manhattan, KS 66506, USA.

${ }^{2}$ Present address: Department of Pharmaceutical Sciences, Skaggs School of Pharmacy and Pharmaceutical Sciences, University of Colorado, Aurora, CO 80045, USA.

Abbreviations: AE, anion exchange; ANOVA, analysis of variance; ATR, atrazine; $\mathrm{C18}$, reverse phase; DACT, didealkylatrazine; DC-FTMS, dual chromatography-Fourier-transform mass spectrometry; DE, desethylatrazine; DIP, desisopropylatrazine; FDR, false discovery rate analysis; LOAEL, lowest observed adverse effect level; $\mathrm{m} / \mathrm{z}$, mass-to-charge ratio; PBPK, physiologically based pharmacokinetic; PCA, principal component analysis; PD, Parkinson's disease; PUFAs, polyunsaturated fatty acids. 


\section{Abstract}

Overexposure to the commonly used herbicide atrazine (ATR) affects several organ systems, including the brain. Previously, we demonstrated that short-term oral ATR exposure causes behavioral deficits and dopaminergic and serotonergic dysfunction in the brains of mice. Using adult male C57BL/6 mice, the present study aimed to investigate effects of a 10-day oral ATR exposure $(0,5,25,125$, or $250 \mathrm{mg} / \mathrm{kg})$ on the mouse plasma metabolome and to determine metabolic pathways affected by ATR that may be reflective of ATR's effects on the brain and useful to identify peripheral biomarkers of neurotoxicity. Four $\mathrm{h}$ after the last dosing on day 10 , plasma was collected and analyzed with high-performance, dual chromatography-Fouriertransform mass spectrometry that was followed by biostatistical and bioinformatic analyses. ATR exposure ( $\geq 5 \mathrm{mg} / \mathrm{kg}$ ) significantly altered plasma metabolite profile and resulted in a dosedependent increase in the number of metabolites with ion intensities significantly different from the control group. Pathway analyses revealed that ATR exposure strongly correlated with and disrupted multiple metabolic pathways. Tyrosine, tryptophan, linoleic acid and a-linolenic acid metabolic pathways were among the affected pathways, with $\alpha$-linolenic acid metabolism being affected to the greatest extent. Observed effects of ATR on plasma tyrosine and tryptophan metabolism may be reflective of the previously reported perturbations of brain dopamine and serotonin homeostasis, respectively. ATR-caused alterations in the plasma profile of $\alpha$-linolenic acid metabolism are a potential novel and sensitive plasma biomarker of ATR effect and plasma metabolomics could be used to better assess the risks, including to the brain, associated with ATR overexposure.

Keywords: Atrazine; Metabolomics; Biomarker; Pesticide; Metabolic pathway analysis; Dual chromatography-Fourier-transform mass spectrometry (DC-FTMS) 


\section{Introduction}

Atrazine (ATR) is a widely used herbicide and the most commonly detected pesticide in the groundwater, soil, and rain in agricultural areas of the US (Majewski et al. 2014; Toccalino et al. 2014). Groundwater ATR concentrations at levels close to the regulatory threshold value of 0.1 $\mu \mathrm{g} / \mathrm{L}$ were reported 20 years after it was banned in Germany (Vonberg et al. 2014); ${ }^{14} \mathrm{C}$-labeled ATR could be detected in soil 22 years after application (Jablonowski et al. 2009), indicating environmental persistence and widespread potential for chronic, environmental exposures to low levels of ATR. Additionally, ATR exposure levels could reach up to 151,000 $\mu \mathrm{g}$ per work shift for ATR manufacturing workers (Catenacci et al. 1993) and $15.0 \mu \mathrm{g} / \mathrm{m}^{3}$ air for ATR applicators (Lozier et al. 2013), suggesting that the occupational exposure levels for ATR are much higher. Due to its widespread presence and continued use in most countries, including the US (EPA 2003), there is an increasing concern about ATR's potential adverse health effects.

In laboratory animals, excessive ATR exposure causes endocrine, reproductive, immune, and especially, nervous systems dysregulations (Cooper et al. 2007; Filipov et al. 2005; Lin et al. 2013a). For example, ATR exposure (50-300 mg/kg) decreases luteinizing hormone surge and disrupts estrous cycle in female rats (Cooper et al. 2007; Cooper et al. 1996). Chronic ATR $(0.03-0.3 \mathrm{mg} / \mathrm{kg})$ exposure also reduces basal metabolic rate, increases body weight and leads to insulin resistance in rats (Lim et al. 2009). Regarding its effects on the brain, we and others have shown in rodents that short-term ( $\geq 25 \mathrm{mg} / \mathrm{kg}$ ), long-term (10 mg/kg), or perinatal (1.4 $\mathrm{mg} / \mathrm{kg}$ ) ATR exposures alter monoamine-associated behaviors and brain dopamine and serotonin homeostasis, suggesting that, in the brain, ATR targets tyrosine and tryptophan metabolism (Bardullas et al. 2011; Lin et al. 2013a; Lin et al. 2014). In line with the rodent studies, epidemiological data based on low, environmental ATR exposure levels report possible endocrine, i.e., menstrual cycle length irregularity (Cragin et al. 2011), metabolic, i.e., increased risk of gestational diabetes mellitus (Saldana et al. 2007), and neurologic, i.e., increased 
incidence of Parkinson's disease (PD; Shaw 2011) perturbations due to ATR. While laboratory and epidemiological data suggests that ATR overexposure is a potential risk factor for reproductive, metabolic and nervous system diseases, its exact mechanisms of toxicity and, importantly, reliable peripheral biomarkers of exposure and/or effect have not been elucidated.

In order to shed light into ATR's mode of action and aid the search for reliable biomarkers of ATR exposure, we developed physiologically based pharmacokinetic (PBPK) models for ATR in rodents of different ages (Lin et al. 2011; Lin et al. 2013b) that can be used for target organ dosimetry based on ATR's peripheral biomarkers of exposure, i.e., plasma/urine levels of ATR and/or its metabolites, desethylatrazine (DE), desisopropylatrazine (DIP), and didealkylatrazine (DACT). We (Ross and Filipov 2006; Ross et al. 2009) and others (Barr et al. 2007; Chevrier et al. 2011; Fraites et al. 2011) have generated rodent and human data on the ATR's kinetics and metabolite profile in plasma and/or urine that, with the help of PBPK modeling, can be used for ATR exposure dosimetry. However, at present, there are no mammalian data that can be used for peripheral biomarkers of ATR's adverse effects. In an effort to discover peripheral biomarkers of toxic effects of environmental contaminants, researchers have begun to employ "metabolomics" approach in combination with bioinformatic and biostatistical methods.

The term "metabolomics" can be defined as "the quantitative measurement of the dynamic multi-parametric metabolic response of living organisms to pathophysiological stimuli or genetic modification" (Nicholson et al. 1999). The advantage of this approach is that it allows rapid detection of both global changes of all metabolites or specific metabolites' changes following exposure to xenobiotics using small amounts of easily accessible biological samples, such as blood or urine (Soltow et al. 2013). These altered metabolites can serve as biomarkers of toxicants' effects and can also be mapped to known biochemical pathways, thereby helping elucidate mechanisms of toxicity. Additionally, this technique can be used to identify novel toxic 
mechanisms because it can detect a large number of metabolites that may be associated with unidentified metabolic pathways (Roede et al. 2012).

Due to the unique advantages of metabolomics, its use in the field of toxicology is expanding rapidly. Recently, metabolomics has been used successfully for identification of sensitive biomarkers of kidney and liver toxicity caused by exposure to fungicides (e.g., carbendazim) (Jones et al. 2013), herbicides (e.g., chlormequat) (Jones et al. 2013), organochlorine (Kim et al. 2009) and organophosphate (e.g., dichlorvos) insecticides in rats (Du et al. 2013; Feng et al. 2012; Hao et al. 2012; Sun et al. 2014; Yang et al. 2011). Besides identifying biomarkers of exposure and toxic effects, these studies have also revealed key metabolic pathways that are associated with the toxicity of each pesticide, highlighting the advantage of metabolomics for elucidation of mechanisms of toxicity and for identification of peripheral biomarkers of toxicity.

In terms of studies on mechanisms of ATR toxicity, metabolomics has been employed to examine effects of chronic ATR exposure on metabolite profiles of the freshwater amphipod Hyalella azteca (Ralston-Hooper et al. 2011). This study identified metabolites (i.e., by-products of $\beta$-oxidation of fatty acids and eicosanoids) affected by ATR that were indicative of ATRinduced perturbations of bioenergetics and hormonal (neuropeptide) homeostasis; it also demonstrated the feasibility of utilizing metabolomics to determine ATR's mechanisms of toxicity in invertebrate species. However, application of metabolomics for investigating ATR's toxic mechanisms or peripheral biomarkers of toxicity in vertebrates, including mammals, has not been reported.

Recently, we established a "top-down" method of metabolic profiling using dual chromatography-Fourier-transform mass spectrometry (DC-FTMS) that provided improved metabolic profiling capability compared to previous platforms (Soltow et al. 2013). Taking 
advantage of this new method and considering the absence of data on biomarkers of ATR's effects in mammals, the objective of this study was to determine the effects of short-term ATR exposure, which we have already demonstrated to cause adverse behavioral and neurochemical effects (Lin et al. 2013a), on the mouse plasma metabolome.

\section{Materials and methods}

\subsection{Chemicals}

Atrazine (Lot \#: 421-55A, 98.9\% purity) was purchased from Chem Service (West Chester, PA). Other chemicals, including corn oil, acetonitrile (HPLC grade), formic acid (LC/MS grade), and water (HPLC grade), unless specified, were obtained from Sigma-Aldrich (St. Louis, MO).

\subsection{Animals, experimental design, and plasma collection}

The animals and the experimental design have been described in detail in our previous publication (Lin et al. 2013a). In brief, adult male C57BL/6 mice were assigned randomly into 5 treatment groups ( $n=4-5 /$ group) and treated daily with corn oil vehicle or a dose range of atrazine $(5,25,125$, or $250 \mathrm{mg} / \mathrm{kg})$ by oral gavage for 10 days. The rationale for this dose regimen selection and its relevance to occupational exposure have been justified in detail in our previous studies with similar or the same exposure paradigms (Coban and Filipov 2007; Filipov et al. 2005; Lin et al. 2013a); these doses are also in line with other short-term exposure studies of ATR's effects on the reproductive, endocrine, and nervous systems (Cooper et al. 2007; Cooper et al. 1996; Fraites et al. 2011; Laws et al. 2009; Rodriguez et al. 2013), allowing parallel comparisons of study findings. Four hours after the last dosing on day 10, mice were deeply anesthetized with $\mathrm{CO}_{2}$, followed by blood collection and euthanasia by decapitation. Blood samples were collected via cardiac puncture in evacuated glass tubes containing $3.2 \%$ buffered sodium citrate solution (BD Vacutainer Systems, Franklin Lakes, NJ), placed on ice on a rocker and centrifuged at $3,100 \times \mathrm{g}$ for $10 \mathrm{~min}$ at $4{ }^{\circ} \mathrm{C}$. Plasma was harvested and stored at - 
$80{ }^{\circ} \mathrm{C}$ until analysis. All animal procedures were performed in accordance with the latest $\mathrm{NIH}$ guidelines and were approved in advance by the Institutional Animal Care and Use Committee (IACUC) of the University of Georgia.

\subsection{Sample preparation and extraction}

The samples were prepared as described by Soltow et al. (2013). Briefly, each plasma aliquot $(50 \mu \mathrm{L})$ was spiked with a $2.5-\mu \mathrm{L}$ internal standard mix consisting of 14 stable isotopic chemicals that represent a broad range of chemical properties of small molecules prior to extraction. Metabolites were extracted by adding $100 \mu \mathrm{L}$ acetonitrile to each $50-\mu \mathrm{L}$ sample and vortexed to mix. The precipitated protein was pelleted via centrifugation and the supernatant was transferred to appropriate vials for LC-MS analysis.

\subsection{LC-MS analysis of plasma extracts}

The LC-MS analysis was done as in Soltow et al. (2013). Briefly, extracts were loaded onto a Shimadzu (Sil-20AC Prominence) autosampler and maintained at $4{ }^{\circ} \mathrm{C}$ until injection. HPLC separation was performed alternately between anion exchange (AE) and reverse phase (C18) columns via a Switchos control valve (LC Packings). The eluate from the HPLC separation was connected to a Thermo LTQ-FTICR mass spectrometer (Thermo Fisher, San Jose, CA). MS analyses were carried out using the mode scanning from an $m / z$ range of $85-850$ in the FT detector at a resolution of 50,000 with the wide range scan mode and $3 \times 10^{6}$ maximum number of ions per scan. The maximum injection time was $500 \mathrm{~ms}$. Each sample was run in duplicate on each column (10 $\mu \mathrm{L}$ injection volume/replicate). Metabolites of interest were subjected to further tandem mass spectrometry analyses to determine molecular structures and for definitive identifications using known standards.

\subsection{Data collection and processing}


Data collection and extraction procedure was according to Soltow et al. (2013). Feature tables containing $\mathrm{m} / \mathrm{z}$ features, retention time, and integrated ion intensities were generated using the apLCMS software package (Yu et al. 2009). The data were further filtered to only include ions that exhibited a coefficient of variation between replicates that was less than $50 \%$ (Soltow et al. 2013). These data were then subjected to further statistical and bioinformatic analyses.

\subsection{Statistics and bioinformatics}

The $\mathrm{m} / \mathrm{z}$ feature data from the AE and C18 columns were compared to determine what $\mathrm{m} / \mathrm{z}$ features were common for both chromatographic techniques using SAS 9.3 for Windows (SAS Institute Inc., Cary, NC). SAS was also used to analyze what $m / z$ features were detected only in control animals or only in ATR-treated animals for each column. Principal component analysis (PCA) was performed using Pirouette version 4.0 (Infometrix, Inc., Bothell, WA). False

Discovery Rate analysis (FDR), with a significance level set at $q=0.05$, was conducted utilizing the Limma package in R. Pearson correlation analysis to determine the metabolites associating with atrazine and/or atrazine's main plasma metabolites was conducted utilizing SAS. Ion intensity data were log-transformed prior to analysis and analyzed with one-way analysis of variance (ANOVA) using GraphPad Prism 5 (GraphPad Software, Inc., La Jolla, CA), followed by Turkey's multiple comparison test post hoc at a significance level of $p<0.05$. Significant metabolites and other metabolites of interest were searched against the Metlin metabolomics database (http://metlin.scripps.edu/index.php) to determine putative identifications (Smith et al. 2005); these metabolites were also analyzed with the MetaboSearch (http://omics.georgetown. edu/metabosearch.html) (Zhou et al. 2012) and the KEGG pathway analysis (http://www.geno me.jp/kegg/) (Kanehisa and Goto 2000) tools to identify metabolic pathways that were affected by ATR or highly correlated with ATR and/or its metabolites.

\section{Results}




\subsection{Metabolite distribution}

To determine any plasma metabolome phenotypic differences caused by ATR exposure, we collected plasma samples from mice orally exposed to vehicle or different concentrations of ATR for 10 days. After analyzing with DC-FTMS, AE column resolved 2,491 m/z and C18 column resolved 3,112 $\mathrm{m} / \mathrm{z}$ (Fig. 1A). Data from both columns were compared to determine what $\mathrm{m} / \mathrm{z}$ features were common among them. This analysis showed that $934 \mathrm{~m} / \mathrm{z}$ were common for both columns, while 1557 and 2178 were unique for AE and C18, respectively (Fig. 1A). Together, these results suggest that the present high performance metabolic profiling technique resolved 4689 unique $\mathrm{m} / \mathrm{z}$ features from plasma samples of mice treated with vehicle or ATR, with the detection performance of the $\mathrm{C} 18$ column being more robust.

Metabolomic data from each column were further analyzed to determine what $\mathrm{m} / \mathrm{z}$ features were detected only in control animals, only in ATR-treated animals, or in both. The AE column data analysis showed that $0.3 \%, 3.2 \%$, and $96.5 \%$ were detected, respectively, only in control animals, only in ATR-treated animals, or in both (Fig. 1B). With the C18 column, $99.6 \%$ of all metabolites were detected in both control and ATR-exposed groups, while $0.4 \%$ were detected only in the ATR-treated groups (Fig. 1C).

\subsection{Metabolic profiling}

To discern the possible presence of inherent clusters in the plasma metabolic profiles of mice receiving different doses of ATR, Principle Component Analysis (PCA), an unsupervised pattern recognition method, was performed (Nicholson et al. 2002). The PCA scores from the C18 column separated ATR-treated from control animals' data points quite well and in a dosedependent manner, except for one outlier from the $25 \mathrm{mg} / \mathrm{kg}$ group (Fig. 2). The dosedependent separation within the ATR-treated animals was quite remarkable and the changes in metabolic profiles from control, to low, to high dose groups occurred in a clockwise direction; 
while clearly separated from the control, there was some overlap between the two lower (25 and $5 \mathrm{mg} / \mathrm{kg}$ ) dose groups (Fig. 2). The PCA scores from the AE column were similar to those from the $\mathrm{C} 18$ column and are not shown. Taken together, these results show that ATR exposure results in a dose-dependent change of the mouse plasma metabolome.

\subsection{Metabolites and metabolic pathways altered by atrazine exposure}

False discovery rate analysis (FDR) was used to determine what $m / z$ features contribute significantly towards between-groups discrimination. FDR results indicated that ATR exposure increased the number of metabolites with significantly different ion intensities dose-dependently (Fig. 3). Specifically, data from the C18 column revealed 3, 5, 27 and $30 \mathrm{~m} / \mathrm{z}$ features that distinguished the $5,25,125$, and $250 \mathrm{mg} / \mathrm{kg}$ dose groups, respectively, from the vehicle group; the corresponding features for the AE column data are 4, 15, 37, and $91 \mathrm{~m} / \mathrm{z}$ (Fig. 3).

To provide putative identities of the differential $\mathrm{m} / \mathrm{z}$ features, $\mathrm{m} / \mathrm{z}$ data were analyzed for matches within $10 \mathrm{ppm}$ with the publically available Metlin database (http://metlin.scripps.edu/index.php). The results are shown in supplementary Table S1 (AE column) and Table S2 (C18 column). Briefly, putative identifications of these $\mathrm{m} / \mathrm{z}$ included fatty acids, dipeptides, tripeptides, ATR and its metabolites, as well as a number of other known and unknown metabolites.

Of the $91 \mathrm{AE} \mathrm{m} / \mathrm{z}$ found to distinguish control and the $250 \mathrm{mg} / \mathrm{kg}$ groups, $52 \mathrm{~m} / \mathrm{z}$ were detected in the $250 \mathrm{mg} / \mathrm{kg}$ group, but not in the control group; $13 \mathrm{~m} / \mathrm{z}$ were detected in the control group, but not in the $250 \mathrm{mg} / \mathrm{kg}$ group; $12 \mathrm{~m} / \mathrm{z}$ had greater ion intensity in $250 \mathrm{mg} / \mathrm{kg}$ group, while 14 $\mathrm{m} / \mathrm{z}$ had greater intensity in control group (Table S1). FDR analysis also revealed $30 \mathrm{C} 18 \mathrm{~m} / \mathrm{z}$ that were different between control and $250 \mathrm{mg} / \mathrm{kg}$ groups. Of these $30 \mathrm{~m} / \mathrm{z}, 6 \mathrm{~m} / \mathrm{z}$ were detected in the $250 \mathrm{mg} / \mathrm{kg}$ group, but not in the control group; $2 \mathrm{~m} / \mathrm{z}$ were detected in the control 
group, but not in the $250 \mathrm{mg} / \mathrm{kg}$ group; $8 \mathrm{~m} / \mathrm{z}$ had greater ion intensity in $250 \mathrm{mg} / \mathrm{kg}$ group, while $14 \mathrm{~m} / \mathrm{z}$ had greater intensity in control group (Table S2).

As expected, ATR and its main metabolites were identified in the ATR-treated mice. C18 column data demonstrate that the ion intensities of ATR and its metabolites (DE, DIP, and DACT) were substantially higher at the higher $(250$ and $125 \mathrm{mg} / \mathrm{kg}$ ) than at the lower (25 and 5 $\mathrm{mg} / \mathrm{kg}$ ) dose groups; the ion intensity of the major end metabolite DACT was increased by ATR ( $\geq 5 \mathrm{mg} / \mathrm{kg}$ ) dose-dependently (Fig. 4). Of note, compared to the ion intensities of ATR, DE and DIP in the $125 \mathrm{mg} / \mathrm{kg}$ group, the corresponding ion intensities were somewhat lower at the 250 $\mathrm{mg} / \mathrm{kg}$ group, likely caused by the previously suggested autoinduction metabolism of ATR (Fraites et al. 2011; Lin et al. 2013b).

To test whether the $m / z$ features that were altered by ATR exposure mapped to metabolic pathways, we used MetaboSearch tool (Zhou et al. 2012) and KEGG pathway analysis (Kanehisa and Goto 2000). MetaboSearch analyses revealed 0, 2, 4, and 4 ATR-altered C18 $\mathrm{m} / z$ matched known KEGG metabolites (compound IDs) in the 5, 25, 125, and $250 \mathrm{mg} / \mathrm{kg}$ dose groups, respectively. After incorporating these KEGG compound IDs into KEGG, analyses showed that ATR ( $\geq 25 \mathrm{mg} / \mathrm{kg}$ ) exposure affected map00791 (atrazine degradation) and map01100 (metabolic pathways) pathways; at higher doses ( $\geq 125 \mathrm{mg} / \mathrm{kg}$ ), ATR also impacted map01120 (microbial metabolism in diverse environments) and map00980 (metabolism of xenobiotics by cytochrome P450) pathways (Table 1).

\subsection{Metabolites and metabolic pathways strongly correlated with atrazine exposure}

Pearson correlation analysis was performed to determine which metabolites were strongly $(r>$ 0.3 or $r<-0.3)$ correlated with ATR, DE, DIP, and/or DACT. C18 data analysis demonstrated that $569,721,744$, and $544 \mathrm{~m} / \mathrm{z}$ were strongly correlated with ATR, DE, DIP, or DACT, 
respectively; $932 \mathrm{~m} / \mathrm{z}$ correlated with at least one of them (Fig. 5). Among these $932 \mathrm{~m} / \mathrm{z}, 394$ $\mathrm{m} / \mathrm{z}$ were correlated with both ATR and DACT, while $365 \mathrm{~m} / \mathrm{z}$ were correlated with ATR and all its three major chlorinated metabolites. In addition, data from AE column showed that 2,172 of the $2,491 \mathrm{~m} / \mathrm{z}$ were correlated with at least one of ATR, DE, DIP or DACT. Of these $2,172 \mathrm{~m} / \mathrm{z}$, 724 and $250 \mathrm{~m} / \mathrm{z}$ were correlated with ATR+DACT and ATR+DE+DIP+DACT, respectively (other data not shown).

To determine which general and specific metabolic pathways are strongly correlated with ATR exposure, the $394 \mathrm{C} 18 \mathrm{~m} / \mathrm{z}$ that correlated with ATR and DACT were analyzed with the aforementioned methods. MetaboSearch analyses showed that $180 \mathrm{~m} / \mathrm{z}$ matched known KEGG metabolites (compound IDs). Of these 180 KEGG metabolites, some are not known to be involved in major metabolic pathways; whereas some can be considered as "benchmark" metabolites and can be present in multiple metabolic pathways. Overall, metabolic pathways with at least 2 mapped metabolites strongly correlated with ATR exposure include map01100 (metabolic pathways), map01110 (biosynthesis of secondary metabolites), map01120 (microbial metabolism in diverse environments), map02010 (ABC transporters), map04974 (protein digestion and absorption), map00592 (a-linolenic acid metabolism), map00591 (linoleic acid metabolism), map00980 (metabolism of xenobiotics by cytochrome P450), map00140 (steroid hormone biosynthesis), and map00380 (tryptophan metabolism) (Table 2). To confirm that the metabolic pathways correlated with ATR corresponded to those correlated DACT, the 569 C18 $\mathrm{m} / \mathrm{z}$ correlated with ATR and the $544 \mathrm{C} 18 \mathrm{~m} / \mathrm{z}$ correlated with DACT were also analyzed with the above-mentioned approach. The results showed that the metabolic pathways that were strongly correlated with ATR were, in most cases and to a similar extent, strongly correlated with DACT or with ATR+DACT (Table 2). These results suggest that the observed alterations related to the major metabolite DACT are consistent with the detected effects associated with ATR. 


\subsection{Potential plasma metabolome biomarkers of atrazine toxicity}

To search for potential plasma biomarkers of ATR toxicity, including for possible peripheral indicators of ATR's effects on the nervous system, strongly correlated $\mathrm{m} / \mathrm{z}$ features were analyzed for matches within $10 \mathrm{ppm}$ with Metlin database. Results showed that tyrosine, leucine/isoleucine, lysoPC(20:3), lysoPC(22:4), carnitine, hexanoylcarnitine, phenylalanine, and stearoylcarnitine were negatively correlated, whereas kynurenic acid, linolenic acid, proglinazine, indolepyruvate, and dihydroxyindole were positively correlated with ATR+DE+DIP+DACT (Table 3). Additionally, tryptophan was negatively correlated with ATR and DACT. From these strongly correlated features, we focused on metabolites from the tyrosine, tryptophan, linoleic acid, and a-linolenic acid metabolism pathways. Tyrosine and tryptophan were selected because in the striatum of mice exposed to the same dose-regimen of ATR, dopamine (tyrosine is a precursor of dopamine) and serotonin (tryptophan is a precursor of serotonin) metabolism were impacted by ATR, with the effects being most prominent at the $125 \mathrm{mg} / \mathrm{kg}$ exposure level (Lin et al. 2013a). Linoleic acid and a-linolenic acid were selected based on a recent metabolomics study with atrazine in hyalella azteca (Ralston-Hooper et al. 2011) which reported that chronic ATR exposure disrupted linoleic acid (linoleate) metabolism pathway by upregulating $Y$-linolenic acid ( $Y$-linolenate).

\subsection{Effects of atrazine exposure on selected metabolic pathways}

To identify specific metabolites, potential reactions, and/or enzymes in selected metabolic pathways that were affected by ATR exposure, we first labeled metabolites that were highly correlated with ATR exposure in these pathways (Fig. 6; "+" and "-" symbols and blue and red color for positive and negative correlation, respectively). Next, we compared the ion intensities of these metabolites between the control and $125 \mathrm{mg} / \mathrm{kg}$ ATR groups with Student's t-test (Table 4). The results revealed a trend towards a significant decrease $(p<0.10, \sim 2$-fold $)$ in the 
ion intensity of beta-tyrosine in ATR-exposed mice, indicating that conversion of L-tyrosine to beta-tyrosine via tyrosine 2,3-aminomutase might by affected by ATR (Table 4 and Fig. 6A). ATR-treated animals also exhibited a trend towards a significant increase $(p<0.10)$ in the ion intensity of indolepyruvate (34-fold) and the indolepyruvate/tryptophan ratio ( 100-fold), indicating a trend towards increased tryptophan metabolism (Table 4 and Fig. 6B). In addition, ATR exposure increased the ion intensities of $\alpha$-linolenic acid and its metabolites (13(S)HpOTrE, 12,13EOTrE, and 12-OPDA), as well as $Y$-linolenic acid and crepenynate (metabolites of linoleic acid), suggesting increased metabolism of linoleic and $\alpha$-linolenic acids (Table 4 and Fig. 6C, 6D).

\section{Discussion}

The major findings of this study are: (1) short-term exposure to as low as $5 \mathrm{mg} / \mathrm{kg}$ ATR induces a dose-dependent change in the mouse plasma metabolome and (2) ATR disrupts multiple critical metabolic pathways, including tyrosine, tryptophan, linoleic acid and $\alpha$-linolenic acid metabolism. Within the context of ATR toxicity studies, these findings are novel.

One of the novel findings from this study is that short-term ATR exposure results in a dosedependent change in the plasma metabolomic profile of mice. The PCA score plot shows that PCA scores for vehicle-treated animals are clearly separated from those of ATR-treated animals at doses as low as $5 \mathrm{mg} / \mathrm{kg}$. Earlier, we reported that these $5 \mathrm{mg} / \mathrm{kg}$ ATR-treated animals did not differ from the vehicle-treated animals in terms of motor, emotional behavior, and brain monoamine homeostasis (Lin et al. 2013a). Similarly, other studies suggest that exposure to 5 mg/kg ATR causes minimal or no significant effects on the immune (Filipov et al. 2005), endocrine (Laws et al. 2009), and nervous systems (Coban and Filipov 2007). The current US EPA no observed adverse effect level (NOAEL) for acute exposure risk assessment of ATR is $10 \mathrm{mg} / \mathrm{kg}$ (EPA 2003), whereas the acute no observed effect level (NOEL) for reproductive and 
developmental endpoints (rabbits) is $5 \mathrm{mg} / \mathrm{kg}$ (Gammon et al. 2005). This finding suggests that plasma metabolomics may be a more sensitive endpoint than other indices evaluated in the literature. Therefore, the plasma metabolic profile may be a reliable and more sensitive global biomarker of ATR effect.

A number of studies with multiple exposure scenarios, i.e., adult short-term or chronic exposures and perinatal exposure to ATR, have shown that ATR disrupts striatal dopamine homeostasis in rodents (Bardullas et al. 2011; Lin et al. 2013a; Lin et al. 2014; Rodriguez et al. 2013), an indication that ATR exposure perturbs tyrosine metabolism. However, information about mechanisms of ATR-induced alterations in tyrosine and/or dopamine metabolism is very limited. Several studies have shown that ATR exposure does not alter the expression of the rate-limiting enzyme in the synthesis of dopamine, tyrosine hydroxylase, in catecholaminergic PC12 cells (Das et al. 2003), rat striatal slices (Filipov et al. 2007), mice (Lin et al. 2013a), and rats (Rodriguez et al. 2013). The present study demonstrates that ATR exposure numerically decreases the ion intensity of the $\mathrm{m} / \mathrm{z}(182.0810, \mathrm{M}+\mathrm{H})$ that is matched to L-tyrosine and also beta-tyrosine (compound ID: C04368; confirmed by MetaboSearch tool and KEGG database). Thus, the increased demand for dopamine that we observed in the striatum of ATR-treated animals ( $\geq 125 \mathrm{mg} / \mathrm{kg}$ ATR; (Lin et al. 2013a) is also reflected by a shift of tyrosine metabolism in the plasma. The potential decrease of beta-tyrosine could be due to ATR-caused inhibition of tyrosine 2,3-aminomutase and it may lead to increased availability of L-tyrosine that is further metabolized to produce dopamine (Fig. 6A); however, this needs to be verified with more sensitive, targeted analysis that reliably quantifies the two forms of tyrosine and by evaluation of ATR's effects on the expression and activity of tyrosine 2,3-aminomutase.

Tyrosine serves many important physiological functions, including being a building block for protein synthesis, a source of energy, and a precursor for the synthesis of melanin and several 
catecholaminergic neurotransmitters, including dopamine (Ferguson et al. 2013). In addition, several recent studies suggest that alterations in tyrosine metabolism are associated with increased risk of developing metabolic diseases, including diabetes and obesity (Cheng et al. 2012; Wang et al. 2011; Wurtz et al. 2012). In this regard, a study using data from the Agricultural Health Study (AHS) showed that ever-use of ATR is associated with increased risk for gestational diabetes mellitus among women who reported agricultural pesticide exposure during the first trimester of pregnancy (Saldana et al. 2007). A laboratory study demonstrated that chronic 5-month exposure to low concentrations of ATR (30 or $300 \mu \mathrm{g} / \mathrm{kg} / \mathrm{day}$ ) via drinking water resulted in decreased basal metabolic rate and increased body weight, intra-abdominal fat, and insulin resistance without changing food intake or physical activity in rats. Obesity and insulin resistance were exacerbated in high-fat diet (40\% fat for 2 months after 3 months of regular diet during the 5-month exposure period) groups compared to the regular diet groups (Lim et al. 2009). Therefore, our current data suggest that ATR exposure disrupts peripheral tyrosine metabolism, which, besides being an indicator of perturbed tyrosine metabolism in the brain, may be partly responsible for the observed association between ATR exposure and metabolic diseases (Lim et al. 2009; Saldana et al. 2007). Further studies examining the role of ATR exposure in the development of metabolic diseases should consider including detailed plasma metabolomics analysis.

Neurochemical data from identical exposure paradigm study showed that ATR (125 or 250 $\mathrm{mg} / \mathrm{kg}$ ) increased striatal levels of serotonin's metabolite, 5-hydroxyindoleacetic acid (5-HIAA), but it did not affect striatal serotonin levels measured at $4 \mathrm{~h}$ after exposure, indicating that ATR increases serotonin metabolism, but the underlying mechanism is unknown (Lin et al. 2013a). The present metabolomics data demonstrate that ATR $(125 \mathrm{mg} / \mathrm{kg})$ exposure numerically decreased tryptophan and increased tryptophan's metabolite indolepyruvate and indolepyruvate/tryptophan ratio. Although these differences lack statistical significance, partially 
due to the ion intensity variability, these data indicate that short-term ATR exposure increases peripheral metabolism of tryptophan, which, when taking place in the brain, explains the previously observed increase of 5-HIAA at $4 \mathrm{~h}$ after 10-day ATR exposure (Lin et al. 2013a). It should be noted that decreased plasma tryptophan will eventually result in decreased precursor availability for serotonin and 5-HIAA synthesis (Biskup et al. 2012), which may ultimately lead to decreased brain serotonin and 5-HIAA levels with continued exposure as recently reported (Rodriguez et al. 2013). This apparent time-dependent effect of ATR on serotonin metabolism should be reflected in the plasma metabolome, but this remains to be investigated. Compared to the non-essential amino acid tyrosine, tryptophan is one of the eight essential amino acids and it is critical for a number of physiological functions, including the synthesis of proteins, kynurenine, melatonin, tryptamine, and serotonin (Richard et al. 2009). In the brain, $90 \%$ of the available tryptophan is metabolized via the kynurenine pathway (Szabo et al. 2011). Some of tryptophan's intermediate metabolites, i.e., quinolinic acid and 3-hydroxy kynurenine, are neurotoxic, while others, such as kynurenic acid, are potentially neuroprotective (Szabo et al. 2011). Disrupted tryptophan metabolism has been demonstrated in several neurological disorders, including in PD (McCusker et al. 2014; Szabo et al. 2011). Our metabolomics data suggest that further studies investigating effects of ATR on tryptophan metabolism in the brain, especially focused on several critical intermediates, including quinolinic acid, 3-hydroxy kynurenine, and kynurenic acid are needed.

Consistent with an earlier study that showed chronic exposure to ATR disrupted linoleic acid metabolism in Hyalella Azteca (Ralston-Hooper et al. 2011), another important and novel finding from the present study is that exposure to a higher dose of ATR (125 mg/kg) disrupts both linoleic acid and $\alpha$-linolenic acid metabolism pathways in mice. Linoleic and $\alpha$-linolenic acids are $\omega-6$ and $\omega-3$ polyunsaturated fatty acids (PUFAs), respectively, which are essential nutrients for mammals. They are parent compounds of eicosanoids and many other long-chain $\omega-6$ and $\omega-3$ 
fatty acids, including eicosapentaenoic acid and docosahexaenoic acid. PUFAs have been shown to possess many physiological functions, including modulation of hormonal, immunological, and anti-inflammatory functions (Schuchardt et al. 2010). In addition, they play a central role in the normal brain development and functioning. For example, PUFAs have the ability to modulate the expression, properties, and action of dopamine and serotonin, especially during the perinatal period when maximal brain growth and development takes place (Das 2013). Chronic imbalance of PUFAs induces abnormalities in dopamine and serotonin neurotransmission in adult rats (Delion et al. 1996) and exposure of rats to PUFA-deficient diet from postnatal day 0 to 70 reduces the number of dopamine neurons in the substantia nigra pars compacta and ventral tegmental area (Ahmad et al. 2008). Clinical plasma metabolomic analyses show that linoleic acid and $\alpha$-linolenic acid metabolic pathways are disrupted in patients with amnestic mild cognitive impairment and with Alzheimer's disease (Wang et al. 2014). Epidemiological studies also demonstrate that imbalance in PUFAs is associated with increased risk of several neurodevelopmental disorders, including attention-deficit/hyperactivity disorder and autism (Caylak 2012; Lyall et al. 2013). In line with these studies, we reported that short-term ATR exposure ( $\geq 125 \mathrm{mg} / \mathrm{kg}$ ) decreased the number of dopamine neurons in the substantia nigra pars compacta and ventral tegmental area in juvenile mice (Coban and Filipov 2007). Additionally, our recent study demonstrated that perinatal exposure to a low dose of ATR $(1.4 \mathrm{mg} / \mathrm{kg})$ resulted in motor and cognitive behavioral abnormalities that were associated with disruption of brain dopamine and serotonin homeostasis in the mouse offspring (Lin et al. 2014). Therefore, the present results suggest that ATR-induced neurotoxicity may be, in part, attributed to disbalance of essential PUFAs, especially linoleic acid and a-linolenic acid, which are novel potential targets of ATR. Combined with the fact that the ion intensities of $\alpha$-linolenic acid and its metabolites (13(S)-HpOTrE, 12,13EOTrE, and 12-OPDA), as well as linoleic acid's metabolites (Y-linolenate and crepenynate) were all consistently and significantly increased by ATR (125 $\mathrm{mg} / \mathrm{kg}$ ) to a greater extent than ion intensity changes caused by ATR exposure for tyrosine or 
tryptophan metabolites, plasma $\alpha$-linolenic acid and its metabolites could be more reliable and robust biomarkers of ATR's adverse effects.

It is worth mentioning that of the $91 \mathrm{AE} \mathrm{m} / \mathrm{z}$ found to separate control from the $250 \mathrm{mg} / \mathrm{kg}$ groups, $52 \mathrm{~m} / \mathrm{z}$ are detected only in the $250 \mathrm{mg} / \mathrm{kg}$ group and $13 \mathrm{~m} / \mathrm{z}$ are present only in the control group. Similar results are found from the $\mathrm{C} 18$ column data. These results indicate that ATR exposure inhibits the production and/or increases the elimination of certain plasma metabolites, and it also induces the generation of metabolites that may otherwise not exist in the normal animals. Even though the high resolution and mass accuracy of the instrument we used (Soltow et al. 2013) gives substantial confidence in the results, the metabolite identification is putative. Putative identities of some of significantly different $\mathrm{m} / \mathrm{z}$ are available in the Metlin database and are provided in Tables S1 and S2. The presence of a number of unidentified $\mathrm{m} / \mathrm{z}$ suggests existence of unknown targets of ATR which should be studied further.

In summary, the present study demonstrates the feasibility of using plasma metabolomics to identify biomarkers and investigate mechanisms of ATR toxicity after short-term exposures. This approach may be also very beneficial in cases of chronic, low-dose exposures, which are more relevant to humans. Of note, for human samples, a non-invasive approach that may be more appropriate is urine-based metabolomics. Urine metabolomics' use is on the rise and it has been used successfully to determine biomarkers and study mechanisms of toxicity caused by chronic low-dose exposures to pesticide mixtures (Du et al. 2013) or individual pesticides (Feng et al. 2012; Hao et al. 2012; Sun et al. 2014; Yang et al. 2011). In addition, urine metabolomics has been shown to be useful in identifying discriminating urine metabolites between reference controls and humans exposed to mixtures of pesticides including ATR (Bonvallot et al. 2013; Chevrier et al. 2011); a urine metabolic signature that distinguishes normal controls from PD patients has been suggested as a useful biomarker for PD (Michell et al. 2008). Therefore, 
future studies using detailed urine metabolomics analyses in addition to plasma metabolomics for biomarker identification exploration of mechanisms of ATR toxicity following chronic lowdose exposures are warranted in both laboratory animals and humans. Metabolomics analyses of urine and/or plasma samples from humans with known recent occupational exposure to ATR are also needed to further evaluate the relevance of this study to humans.

\section{Conclusions}

The present study shows that short-term exposure to ATR causes dose-dependent changes in the plasma metabolome that include aromatic amino acid, PUFA and other metabolic pathways. Application of a high-resolution metabolomics analysis to a mouse model of ATR toxicity with documented behavioral and neurochemical deficits provides plasma correlate, dysregulated peripheral tyrosine and tryptophan metabolism for the central alterations of brain dopamine and serotonin homeostasis; it also identifies additional novel disruption of essential fatty acid metabolism and demonstrates widespread metabolic effects beginning at concentrations below those currently recognized as toxic. Overall, global alterations in the plasma metabolome and specific effects on $\alpha$-linolenate metabolism are potential novel and sensitive biomarkers of ATR toxicity.

\section{Conflict of interest statement}

The authors declare that there are no conflicts of interest. 


\section{References:}

Ahmad, S.O., Park, J.H., Radel, J.D. and Levant, B. 2008. Reduced numbers of dopamine neurons in the substantia nigra pars compacta and ventral tegmental area of rats fed an n-3 polyunsaturated fatty acid-deficient diet: a stereological study. Neuroscience letters 438, 303307.

Bardullas, U., Giordano, M. and Rodriguez, V.M. 2011. Chronic atrazine exposure causes disruption of the spontaneous locomotor activity and alters the striatal dopaminergic system of the male Sprague-Dawley rat. Neurotoxicol. Teratol. 33, 263-272.

Barr, D.B., Panuwet, P., Nguyen, J.V., Udunka, S. and Needham, L.L. 2007. Assessing exposure to atrazine and its metabolites using biomonitoring. Environmental health perspectives $115,1474-1478$.

Biskup, C.S., Sanchez, C.L., Arrant, A., Van Swearingen, A.E., Kuhn, C. and Zepf, F.D. 2012. Effects of acute tryptophan depletion on brain serotonin function and concentrations of dopamine and norepinephrine in C57BL/6J and BALB/cJ mice. PloS one 7, e35916.

Bonvallot, N., Tremblay-Franco, M., Chevrier, C., Canlet, C., Warembourg, C., Cravedi, J.P. and Cordier, S. 2013. Metabolomics tools for describing complex pesticide exposure in pregnant women in Brittany (France). PloS one 8, e64433.

Catenacci, G., Barbieri, F., Bersani, M., Ferioli, A., Cottica, D. and Maroni, M. 1993. Biological monitoring of human exposure to atrazine. Toxicology letters 69, 217-222.

Caylak, E. 2012. Biochemical and genetic analyses of childhood attention deficit/hyperactivity disorder. American journal of medical genetics. Part B, Neuropsychiatric genetics : the official publication of the International Society of Psychiatric Genetics 159B, 613-627. 
Cheng, S., Rhee, E.P., Larson, M.G., Lewis, G.D., McCabe, E.L., Shen, D., Palma, M.J., Roberts, L.D., Dejam, A., Souza, A.L., Deik, A.A., Magnusson, M., Fox, C.S., O'Donnell, C.J., Vasan, R.S., Melander, O., Clish, C.B., Gerszten, R.E. and Wang, T.J. 2012. Metabolite profiling identifies pathways associated with metabolic risk in humans. Circulation 125, 22222231.

Chevrier, C., Limon, G., Monfort, C., Rouget, F., Garlantezec, R., Petit, C., Durand, G. and Cordier, S. 2011. Urinary biomarkers of prenatal atrazine exposure and adverse birth outcomes in the PELAGIE birth cohort. Environmental health perspectives 119, 1034-1041.

Coban, A. and Filipov, N.M. 2007. Dopaminergic toxicity associated with oral exposure to the herbicide atrazine in juvenile male C57BL/6 mice. J Neurochem 100, 1177-1187.

Cooper, R.L., Laws, S.C., Das, P.C., Narotsky, M.G., Goldman, J.M., Lee Tyrey, E. and Stoker, T.E. 2007. Atrazine and reproductive function: mode and mechanism of action studies. Birth Defects Res. B Dev. Reprod. Toxicol 80, 98-112.

Cooper, R.L., Stoker, T.E., Goldman, J.M., Parrish, M.B. and Tyrey, L. 1996. Effect of atrazine on ovarian function in the rat. Reprod. Toxicol. 10, 257-264.

Cragin, L.A., Kesner, J.S., Bachand, A.M., Barr, D.B., Meadows, J.W., Krieg, E.F. and Reif, J.S. 2011. Menstrual cycle characteristics and reproductive hormone levels in women exposed to atrazine in drinking water. Environ. Res. 111, 1293-1301.

Das, P.C., McElroy, W.K. and Cooper, R.L. 2003. Potential mechanisms responsible for chlorotriazine-induced alterations in catecholamines in pheochromocytoma (PC12) cells. Life sciences 73, 3123-3138. 
Das, U.N. 2013. Autism as a disorder of deficiency of brain-derived neurotrophic factor and altered metabolism of polyunsaturated fatty acids. Nutrition 29, 1175-1185.

Delion, S., Chalon, S., Guilloteau, D., Besnard, J.C. and Durand, G. 1996. alpha-Linolenic acid dietary deficiency alters age-related changes of dopaminergic and serotoninergic neurotransmission in the rat frontal cortex. J Neurochem 66, 1582-1591.

Du, L., Wang, H., Xu, W., Zeng, Y., Hou, Y., Zhang, Y., Zhao, X. and Sun, C. 2013. Application of ultraperformance liquid chromatography/mass spectrometry-based metabonomic techniques to analyze the joint toxic action of long-term low-level exposure to a mixture of organophosphate pesticides on rat urine profile. Toxicol. Sci. 134, 195-206.

EPA. 2003. Interim Reregistration Eligibility Decision for Atrazine. Case No. 0062, available at URL: http://www.epa.gov/oppsrrd1/REDs/atrazine ired.pdf. U.S. Environmental Protection Agency, Washington, DC. . pp. 15-52.

Feng, Z., Sun, X., Yang, J., Hao, D., Du, L., Wang, H., Xu, W., Zhao, X. and Sun, C. 2012. Metabonomics analysis of urine and plasma from rats given long-term and low-dose dimethoate by ultra-performance liquid chromatography-mass spectrometry. Chem. Biol. Interact. 199, 143153.

Ferguson, A.A., Roy, S., Kormanik, K.N., Kim, Y., Dumas, K.J., Ritov, V.B., Matern, D., Hu, P.J. and Fisher, A.L. 2013. TATN-1 mutations reveal a novel role for tyrosine as a metabolic signal that influences developmental decisions and longevity in Caenorhabditis elegans. PLoS genetics 9, e1004020.

Filipov, N.M., Pinchuk, L.M., Boyd, B.L. and Crittenden, P.L. 2005. Immunotoxic effects of shortterm atrazine exposure in young male C57BL/6 mice. Toxicological sciences : an official journal of the Society of Toxicology $86,324-332$. 
Filipov, N.M., Stewart, M.A., Carr, R.L. and Sistrunk, S.C. 2007. Dopaminergic toxicity of the herbicide atrazine in rat striatal slices. Toxicology 232, 68-78.

Fraites, M.J., Narotsky, M.G., Best, D.S., Stoker, T.E., Davis, L.K., Goldman, J.M., Hotchkiss, M.G., Klinefelter, G.R., Kamel, A., Qian, Y., Podhorniak, L. and Cooper, R.L. 2011. Gestational atrazine exposure: effects on male reproductive development and metabolite distribution in the dam, fetus, and neonate. Reprod. Toxicol. 32, 52-63.

Gammon, D.W., Aldous, C.N., Carr, W.C., Jr., Sanborn, J.R. and Pfeifer, K.F. 2005. A risk assessment of atrazine use in California: human health and ecological aspects. Pest management science 61, 331-355.

Hao, D.F., Xu, W., Wang, H., Du, L.F., Yang, J.D., Zhao, X.J. and Sun, C.H. 2012. Metabolomic analysis of the toxic effect of chronic low-dose exposure to acephate on rats using ultraperformance liquid chromatography/mass spectrometry. Ecotoxicol. Environ. Saf. 83, 25-33.

Jablonowski, N.D., Koppchen, S., Hofmann, D., Schaffer, A. and Burauel, P. 2009. Persistence of 14C-labeled atrazine and its residues in a field lysimeter soil after 22 years. Environ. Pollut. $157,2126-2131$.

Jones, O.A., Murfitt, S., Svendsen, C., Turk, A., Turk, H., Spurgeon, D.J., Walker, L.A., Shore, R.F., Long, S.M. and Griffin, J.L. 2013. Comparisons of metabolic and physiological changes in rats following short term oral dosing with pesticides commonly found in food. Food Chem. Toxicol. 59, 438-445.

Kanehisa, M. and Goto, S. 2000. KEGG: kyoto encyclopedia of genes and genomes. Nucleic Acids Res. 28, 27-30. 
Kim, K.B., Kim, S.H., Um, S.Y., Chung, M.W., Oh, J.S., Jung, S.C., Kim, T.S., Moon, H.J., Han, S.Y., Oh, H.Y., Lee, B.M. and Choi, K.H. 2009. Metabolomics approach to risk assessment: methoxyclor exposure in rats. J. Toxicol. Environ. Health A 72, 1352-1368.

Laws, S.C., Hotchkiss, M., Ferrell, J., Jayaraman, S., Mills, L., Modic, W., Tinfo, N., Fraites, M., Stoker, T. and Cooper, R. 2009. Chlorotriazine herbicides and metabolites activate an ACTHdependent release of corticosterone in male Wistar rats. Toxicological sciences : an official journal of the Society of Toxicology 112, 78-87.

Lim, S., Ahn, S.Y., Song, I.C., Chung, M.H., Jang, H.C., Park, K.S., Lee, K.U., Pak, Y.K. and Lee, H.K. 2009. Chronic exposure to the herbicide, atrazine, causes mitochondrial dysfunction and insulin resistance. PloS one 4, e5186.

Lin, Z., Dodd, C.A. and Filipov, N.M. 2013a. Short-term atrazine exposure causes behavioral deficits and disrupts monoaminergic systems in male C57BL/6 mice. Neurotoxicol. Teratol. 39C, 26-35.

Lin, Z., Dodd, C.A., Xiao, S., Krishna, S., Ye, X. and Filipov, N.M. 2014. Gestational and Lactational Exposure to Atrazine Via the Drinking Water Causes Specific Behavioral Deficits and Selectively Alters Monoaminergic Systems in C57BL/6 Mouse Dams, Juvenile and Adult Offspring. Toxicological sciences : an official journal of the Society of Toxicology.

Lin, Z., Fisher, J.W., Ross, M.K. and Filipov, N.M. 2011. A physiologically based pharmacokinetic model for atrazine and its main metabolites in the adult male C57BL/6 mouse. Toxicol. Appl. Pharmacol. 251, 16-31.

Lin, Z., Fisher, J.W., Wang, R., Ross, M.K. and Filipov, N.M. 2013b. Estimation of placental and lactational transfer and tissue distribution of atrazine and its main metabolites in rodent dams, 
fetuses, and neonates with physiologically based pharmacokinetic modeling. Toxicol. Appl. Pharmacol. 273, 140-158.

Lozier, M.J., Montoya, J.F., Del Rosario, A., Martinez, E.P., Fuortes, L., Cook, T.M. and Sanderson, W.T. 2013. Personal air sampling and risks of inhalation exposure during atrazine application in Honduras. International archives of occupational and environmental health 86, 479-488.

Lyall, K., Munger, K.L., O'Reilly, E.J., Santangelo, S.L. and Ascherio, A. 2013. Maternal dietary fat intake in association with autism spectrum disorders. American journal of epidemiology 178, 209-220.

Majewski, M.S., Coupe, R.H., Foreman, W.T. and Capel, P.D. 2014. Pesticides in Mississippi air and rain: A comparison between 1995 and 2007. Environmental toxicology and chemistry / SETAC.

McCusker, R.H., Kavelaars, A., Heijnen, C.J., Dantzer, R. and Kelley, K.W. 2014. Depression, inflammation and tryptophan metabolism. In: A.W. Kusnecov and H. Anisman (Eds), The WileyBlackwell Handbook of Psychoneuroimmunology, John Wiley \& Sons LtD, West Sussex, UK, pp. 448-468.

Michell, A.W., Mosedale, D., Grainger, D.J. and Barker, R.A. 2008. Metabolomic analysis of urine and serum in Parkinson's disease. Metabolomics 4, 191-201.

Nicholson, J.K., Connelly, J., Lindon, J.C. and Holmes, E. 2002. Metabonomics: a platform for studying drug toxicity and gene function. Nature reviews. Drug discovery 1, 153-161.

Nicholson, J.K., Lindon, J.C. and Holmes, E. 1999. 'Metabonomics': understanding the metabolic responses of living systems to pathophysiological stimuli via multivariate statistical 
analysis of biological NMR spectroscopic data. Xenobiotica; the fate of foreign compounds in biological systems 29, 1181-1189.

Ralston-Hooper, K.J., Adamec, J., Jannash, A., Mollenhauer, R., Ochoa-Acuna, H. and Sepulveda, M.S. 2011. Use of GC x GC/TOF-MS and LC/TOF-MS for metabolomic analysis of Hyalella azteca chronically exposed to atrazine and its primary metabolite, desethylatrazine. J. Appl. Toxicol. 31, 399-410.

Richard, D.M., Dawes, M.A., Mathias, C.W., Acheson, A., Hill-Kapturczak, N. and Dougherty, D.M. 2009. L-Tryptophan: Basic Metabolic Functions, Behavioral Research and Therapeutic Indications. International journal of tryptophan research : IJTR 2, 45-60.

Rodriguez, V.M., Limon-Pacheco, J.H., Mendoza-Trejo, M.S., Gonzalez-Gallardo, A., Hernandez-Plata, I. and Giordano, M. 2013. Repeated exposure to the herbicide atrazine alters locomotor activity and the nigrostriatal dopaminergic system of the albino rat. Neurotoxicology 34, $82-94$.

Roede, J.R., Park, Y., Li, S., Strobel, F.H. and Jones, D.P. 2012. Detailed mitochondrial phenotyping by high resolution metabolomics. PloS one 7, e33020.

Ross, M.K. and Filipov, N.M. 2006. Determination of atrazine and its metabolites in mouse urine and plasma by LC-MS analysis. Analytical biochemistry 351, 161-173.

Ross, M.K., Jones, T.L. and Filipov, N.M. 2009. Disposition of the herbicide 2-chloro-4(ethylamino)-6-(isopropylamino)-s-triazine (Atrazine) and its major metabolites in mice: a liquid chromatography/mass spectrometry analysis of urine, plasma, and tissue levels. Drug metabolism and disposition: the biological fate of chemicals $37,776-786$. 
Saldana, T.M., Basso, O., Hoppin, J.A., Baird, D.D., Knott, C., Blair, A., Alavanja, M.C. and Sandler, D.P. 2007. Pesticide exposure and self-reported gestational diabetes mellitus in the Agricultural Health Study. Diabetes care 30, 529-534.

Schuchardt, J.P., Huss, M., Stauss-Grabo, M. and Hahn, A. 2010. Significance of long-chain polyunsaturated fatty acids (PUFAs) for the development and behaviour of children. European journal of pediatrics $169,149-164$.

Shaw, G. 2011. New evidence for association of pesticides with Parkinson Disease. Neurology Today $11,1,16-21$.

Smith, C.A., O'Maille, G., Want, E.J., Qin, C., Trauger, S.A., Brandon, T.R., Custodio, D.E., Abagyan, R. and Siuzdak, G. 2005. METLIN: a metabolite mass spectral database. Therapeutic drug monitoring $27,747-751$.

Soltow, Q.A., Strobel, F.H., Mansfield, K.G., Wachtman, L., Park, Y. and Jones, D.P. 2013. High-performance metabolic profiling with dual chromatography-Fourier-transform mass spectrometry (DC-FTMS) for study of the exposome. Metabolomics 9, 132-143.

Sun, X., Xu, W., Zeng, Y., Hou, Y., Guo, L., Zhao, X. and Sun, C. 2014. Metabonomics evaluation of urine from rats administered with phorate under long-term and low-level exposure by ultra-performance liquid chromatography-mass spectrometry. J. Appl. Toxicol. 34, 176-183.

Szabo, N., Kincses, Z.T., Toldi, J. and Vecsei, L. 2011. Altered tryptophan metabolism in Parkinson's disease: a possible novel therapeutic approach. Journal of the neurological sciences 310, 256-260.

Toccalino, P.L., Gilliom, R.J., Lindsey, B.D. and Rupert, M.G. 2014. Pesticides in Groundwater of the United States: Decadal-Scale Changes, 1993-2011. Ground water. 
Vonberg, D., Vanderborght, J., Cremer, N., Putz, T., Herbst, M. and Vereecken, H. 2014. 20 years of long-term atrazine monitoring in a shallow aquifer in western Germany. Water research 50, 294-306.

Wang, G., Zhou, Y., Huang, F.J., Tang, H.D., Xu, X.H., Liu, J.J., Wang, Y., Deng, Y.L., Ren, R.J., Xu, W., Ma, J.F., Zhang, Y.N., Zhao, A.H., Chen, S.D. and Jia, W. 2014. Plasma Metabolite Profiles of Alzheimer's Disease and Mild Cognitive Impairment. Journal of proteome research.

Wang, T.J., Larson, M.G., Vasan, R.S., Cheng, S., Rhee, E.P., McCabe, E., Lewis, G.D., Fox, C.S., Jacques, P.F., Fernandez, C., O'Donnell, C.J., Carr, S.A., Mootha, V.K., Florez, J.C., Souza, A., Melander, O., Clish, C.B. and Gerszten, R.E. 2011. Metabolite profiles and the risk of developing diabetes. Nature medicine 17, 448-453.

Wurtz, P., Tiainen, M., Makinen, V.P., Kangas, A.J., Soininen, P., Saltevo, J., KeinanenKiukaanniemi, S., Mantyselka, P., Lehtimaki, T., Laakso, M., Jula, A., Kahonen, M., Vanhala, M. and Ala-Korpela, M. 2012. Circulating metabolite predictors of glycemia in middle-aged men and women. Diabetes care 35, 1749-1756.

Yang, J., Sun, X., Feng, Z., Hao, D., Wang, M., Zhao, X. and Sun, C. 2011. Metabolomic analysis of the toxic effects of chronic exposure to low-level dichlorvos on rats using ultraperformance liquid chromatography-mass spectrometry. Toxicol. Lett. 206, 306-313.

Yu, T., Park, Y., Johnson, J.M. and Jones, D.P. 2009. apLCMS--adaptive processing of highresolution LC/MS data. Bioinformatics 25, 1930-1936.

Zhou, B., Wang, J. and Ressom, H.W. 2012. MetaboSearch: tool for mass-based metabolite identification using multiple databases. PloS one 7, e40096. 


\section{Figure legends}

Fig. 1. Distribution of plasma metabolites of vehicle- vs. atrazine (ATR)-exposed male C57BL/6 mice resolved by anion exchange $(\mathrm{AE})$ and reverse phase $(\mathrm{C} 18)$ chromatography. Data from both columns were compared to determine common for both chromatographic techniques metabolites (A). Data from each column were further analyzed to determine metabolites that were detected only in control animals, only in ATR-treated animals, or in both groups. B and C represent $A E$ and $C 18$ columns, respectively.

Fig. 2. Principal component analysis (PCA) score plot results comparing plasma metabolic profiles of vehicle- vs. atrazine (ATR)-treated male C57BL/6 mice from the C18 column.

Fig. 3. Number of metabolites altered by atrazine (ATR) exposure. Data were analyzed with false discovery rate (FDR) analysis with significance level set at $q=0.05$. $A$ and $B$ represent data from anion exchange $(\mathrm{AE})$ and reverse phase $(\mathrm{C} 18)$ columns, respectively.

Fig. 4. Ion intensities of atrazine (ATR) (A) and its metabolites DE (B), DIP (C), and DACT (D) in plasma samples from vehicle- and ATR-treated male C57BL/6 mice determined with the C18 column. * Indicates significant difference from the control group $(p<0.05) .{ }^{\wedge}$ Indicates significant difference compared to the $5 \mathrm{mg} / \mathrm{kg}$ group $(\mathrm{p}<0.05)$. Ion intensity data were log-transformed and then analyzed with one-way ANOVA, followed by Turkey's multiple comparison post hoc test.

Fig. 5. Number of metabolites (C18 column) that were strongly correlated (defined as Pearson's $r>0.3$ or $r<-0.3)$ with atrazine $($ ATR), and/or its metabolites DE, DIP, and DACT. 
Fig. 6. Short-term atrazine (ATR, $125 \mathrm{mg} / \mathrm{kg}$ ) exposure disrupts tyrosine (A), tryptophan (B), linoleic acid (C), and a-linolenic acid (D) metabolism pathways in male C57BL/6 mice. Metabolites in green color represent metabolites that were increased by ATR and/or highly positively correlated (Pearson's $r>0.3$ ) with ATR exposure. Metabolites in red color represent metabolites that were decreased by ATR and/or highly negatively correlated (Pearson's $r<-0.3$ ) with ATR exposure. "+" and "-" symbols represent positive and negative correlations, respectively. Green upward and red downward arrow(s) indicate an increase or a decrease caused by ATR. Please refer to the Results Section 3.6 and Table 4 for more detailed description. Abbreviations for enzymes in textboxes are as follows: AAAH: aromatic amino acid hydroxylase; AAO: L-amino-acid oxidase; AFMID: arylformamidase; ALOX15: arachidonate 15lipoxygenase; AO: acetylindoxyl oxidase; aoc: allene oxide cyclase; AOS: hydroperoxide dehydratase; CCBL: kynurenine-oxoglutarate transaminase/cysteine-S-conjugate beta-lyase; DDC: aromatic-L-amino-acid decarboxylase; DFAD: delta12-fatty acid dehydrogenase; INDO: indoleamine 2,3-dioxygenase; L9L: linoleate 9S-lipoxygenase; LCD: linoleoyl-CoA desaturase; LOX2S: lipoxygenase; MAO: monoamine oxidase; OAR: 12-oxophytodienoic acid reductase; PLA2G: secretory phospholipase A2; PLA2G16: HRAS-like suppressor 3; PO: polyphenol oxidase; TA: tyrosine 2,3-aminomutase; TAA1: L-tryptophan-pyruvate aminotransferase; Tam1: tryptophan aminotransferase; TDC: tyrosine decarboxylase; TDO2: tryptophan 2,3-dioxygenase; TH: tyrosine hydroxylase; tnaA: tryptophanase; TPH1_2: tryptophan 5-monooxygenase; TYR: tyrosinase. 
Table 1. Metabolic pathways affected by 10-day oral atrazine (ATR) exposure in male C57BL/6 mice.

\begin{tabular}{lll}
\hline Pathway ID & Pathway definition & \# of mapped metabolites \\
\hline $5 \mathrm{mg} / \mathrm{kg}$ & & - \\
\hline & & \\
$25 \mathrm{mg} / \mathrm{kg}$ & & 2 \\
map00791 & Atrazine degradation & 2 \\
map01120 & Microbial metabolism in diverse environments & 1 \\
map01100 & Metabolic pathways & \\
& & 3 \\
$125 \mathrm{mg} / \mathrm{kg}$ & & 3 \\
map00791 & Atrazine degradation & 1 \\
map01120 & Microbial metabolism in diverse environments & 1 \\
map00980 & Metabolism of xenobiotics by cytochrome P450 & \\
map01100 & Metabolic pathways & 3 \\
$250 \mathrm{mg} / \mathrm{kg}$ & & \\
map00791 & Atrazine degradation & 3 \\
map01120 & Microbial metabolism in diverse environments & 1 \\
map00980 & Metabolism of xenobiotics by cytochrome P450 & 1 \\
\hline map01100 & Metabolic pathways & 3 \\
\hline
\end{tabular}


Table 2. Metabolic pathways with at least 2 mapped metabolites that are strongly correlated with atrazine (ATR) and/or its major metabolite DACT.

\begin{tabular}{|c|c|c|c|c|}
\hline \multirow[t]{2}{*}{ Pathway ID } & \multirow[t]{2}{*}{ Pathway definition } & \multicolumn{3}{|c|}{ \# of mapped metabolites } \\
\hline & & ATR & DACT & ATR+DACT \\
\hline map01100 & Metabolic pathways & 30 & 29 & 21 \\
\hline map01110 & Biosynthesis of secondary metabolites & 14 & 15 & 11 \\
\hline map01120 & Microbial metabolism in diverse environments & 10 & 8 & 8 \\
\hline map01060 & Biosynthesis of plant secondary metabolites & 9 & 9 & 8 \\
\hline map02010 & $\mathrm{ABC}$ transporters & 7 & 7 & 7 \\
\hline map00280 & Valine, leucine and isoleucine degradation & 6 & 6 & 6 \\
\hline map04978 & Mineral absorption & 5 & 6 & 5 \\
\hline map04974 & Protein digestion and absorption & 5 & 6 & 5 \\
\hline map01230 & Biosynthesis of amino acids & 5 & 6 & 5 \\
\hline map01210 & 2-Oxocarboxylic acid metabolism & 5 & 6 & 5 \\
\hline map00970 & Aminoacyl-tRNA biosynthesis & 5 & 6 & 5 \\
\hline map00966 & Glucosinolate biosynthesis & 5 & 6 & 5 \\
\hline map00592 & a-Linolenic acid metabolism & 6 & 5 & 5 \\
\hline map00791 & Atrazine degradation & 4 & 4 & 4 \\
\hline map00591 & Linoleic acid metabolism & 10 & 4 & 4 \\
\hline map00290 & Valine, leucine and isoleucine biosynthesis & 4 & 4 & 4 \\
\hline map00121 & Secondary bile acid biosynthesis & 4 & 8 & 4 \\
\hline map01070 & Biosynthesis of plant hormones & 4 & 4 & 3 \\
\hline map01065 & $\begin{array}{l}\text { Biosynthesis of alkaloids derived from histidine and } \\
\text { purine }\end{array}$ & 3 & 3 & 3 \\
\hline map01064 & $\begin{array}{l}\text { Biosynthesis of alkaloids derived from ornithine, } \\
\text { lysine and nicotinic acid }\end{array}$ & 3 & 3 & 3 \\
\hline map00980 & Metabolism of xenobiotics by cytochrome P450 & 3 & 3 & 3 \\
\hline map00960 & $\begin{array}{l}\text { Tropane, piperidine and pyridine alkaloid } \\
\text { biosynthesis }\end{array}$ & 3 & 3 & 3 \\
\hline map00460 & Cyanoamino acid metabolism & 3 & 3 & 3 \\
\hline map00140 & Steroid hormone biosynthesis & 3 & 7 & 3 \\
\hline map07033 & Anticonvulsants & 2 & 2 & 2 \\
\hline map04976 & Bile secretion & 2 & 3 & 2 \\
\hline map01040 & Biosynthesis of unsaturated fatty acids & 2 & 2 & 2 \\
\hline map00930 & Caprolactam degradation & 2 & 2 & 2 \\
\hline map00906 & Carotenoid biosynthesis & 2 & 2 & 2 \\
\hline map00562 & Inositol phosphate metabolism & 2 & 2 & 2 \\
\hline map00522 & $\begin{array}{l}\text { Biosynthesis of 12-, 14- and 16-membered } \\
\text { macrolides }\end{array}$ & 6 & 2 & 2 \\
\hline map00380 & Tryptophan metabolism & 2 & 2 & 2 \\
\hline map00981 & Insect hormone biosynthesis & 1 & 2 & 1 \\
\hline map03320 & PPAR signaling pathway & 2 & 0 & 0 \\
\hline
\end{tabular}


Table 3. Metabolites of interest that are strongly correlated with atrazine (ATR) exposure.

\begin{tabular}{|c|c|c|c|c|c|c|c|}
\hline $\mathrm{m} / \mathrm{z}$ & $\begin{array}{l}\text { Retention } \\
\text { time (s) }\end{array}$ & Metabolite name & Formula & Adduct & ppm & $\begin{array}{l}\text { Correlation } \\
\text { coefficient }\end{array}$ & $\begin{array}{l}\text { Correlated } \\
\text { atrazine/metabolites }\end{array}$ \\
\hline 182.081 & 104.878 & Tyrosine & $\mathrm{C} 9 \mathrm{H} 11 \mathrm{NO} 3$ & $\mathrm{M}+\mathrm{H}$ & 0 & -0.60 & $\mathrm{ATR}+\mathrm{DE}+\mathrm{DIP}+\mathrm{DACT}$ \\
\hline 132.102 & 192.841 & Leucine/lsoleucine & $\mathrm{C} 6 \mathrm{H} 13 \mathrm{NO} 2$ & $\mathrm{M}+\mathrm{H}$ & 3 & -0.56 & $\mathrm{ATR}+\mathrm{DE}+\mathrm{DIP}+\mathrm{DACT}$ \\
\hline 546.355 & 518.894 & LysoPC(20:3) & C28H52NO7P & $\mathrm{M}+\mathrm{H}$ & 1 & -0.52 & $\mathrm{ATR}+\mathrm{DE}+\mathrm{DIP}+\mathrm{DACT}$ \\
\hline 572.367 & 529.039 & LysoPC(22:4) & C30H54NO7P & $\mathrm{M}+\mathrm{H}$ & 7 & -0.51 & $\mathrm{ATR}+\mathrm{DE}+\mathrm{DIP}+\mathrm{DACT}$ \\
\hline 162.112 & 102.706 & Carnitine & C7H15NO3 & $\mathrm{M}+\mathrm{H}$ & 1 & -0.50 & $\mathrm{ATR}+\mathrm{DE}+\mathrm{DIP}+\mathrm{DACT}$ \\
\hline 260.187 & 521.723 & Hexanoylcarnitine & $\mathrm{C} 13 \mathrm{H} 25 \mathrm{NO} 4$ & $\mathrm{M}+\mathrm{H}$ & 4 & -0.44 & $\mathrm{ATR}+\mathrm{DE}+\mathrm{DIP}+\mathrm{DACT}$ \\
\hline 166.086 & 100.046 & Phenylalanine & $\mathrm{C} 9 \mathrm{H} 11 \mathrm{NO} 2$ & $\mathrm{M}+\mathrm{H}$ & 1 & -0.36 & $A T R+D E+D I P+D A C T$ \\
\hline 428.376 & 499.214 & Stearoylcarnitine & $\mathrm{C} 25 \mathrm{H} 49 \mathrm{NO} 4$ & $\mathrm{M}+\mathrm{H}$ & 5 & -0.36 & $A T R+D E+D I P+D A C T$ \\
\hline 190.050 & 525.208 & Kynurenic acid & $\mathrm{C} 10 \mathrm{H} 7 \mathrm{NO} 3$ & $\mathrm{M}+\mathrm{H}$ & 1 & 0.42 & $\mathrm{ATR}+\mathrm{DE}+\mathrm{DIP}+\mathrm{DACT}$ \\
\hline 279.233 & 507.641 & Linolenic Acid & $\mathrm{C} 18 \mathrm{H} 30 \mathrm{O} 2$ & $\mathrm{M}+\mathrm{H}$ & 2 & 0.53 & $A T R+D E+D I P+D A C T$ \\
\hline 246.075 & 173.374 & Proglinazine & $\mathrm{C} 8 \mathrm{H} 12 \mathrm{CIN} 5 \mathrm{O} 2$ & $\mathrm{M}+\mathrm{H}$ & 1 & 0.60 & $\mathrm{ATR}+\mathrm{DE}+\mathrm{DIP}+\mathrm{DACT}$ \\
\hline 204.064 & 149.866 & Indolepyruvate & C11H9NO3 & $\mathrm{M}+\mathrm{H}$ & 5 & 0.67 & $A T R+D E+D I P+D A C T$ \\
\hline 172.038 & 122.136 & Dihydroxyindole & $\mathrm{C} 8 \mathrm{H} 7 \mathrm{NO} 2$ & $\mathrm{M}+\mathrm{Na}$ & 6 & 0.84 & $A T R+D E+D I P+D A C T$ \\
\hline 205.097 & 105.479 & Tryptophan & $\mathrm{C} 11 \mathrm{H} 12 \mathrm{~N} 2 \mathrm{O} 2$ & $\mathrm{M}+\mathrm{H}$ & 1 & -0.57 & ATR+DACT \\
\hline 450.358 & 468.727 & Stearoylcarnitine & $\mathrm{C} 25 \mathrm{H} 49 \mathrm{NO} 4$ & $\mathrm{M}+\mathrm{Na}$ & 5 & 0.31 & ATR+DACT \\
\hline
\end{tabular}


Table 4. Ion intensities (mean \pm SEM) of metabolites of interest in control and atrazine (ATR)-treated (125 mg/kg) groups.

\begin{tabular}{|c|c|c|c|c|c|}
\hline Pathway/Metabolite & $\mathrm{m} / \mathrm{z}$ ratio & Adduct & Control & $125 \mathrm{mg} / \mathrm{kg}$ atrazine & $p$ value \\
\hline \multicolumn{6}{|l|}{ Tyrosine metabolism } \\
\hline Beta-tyrosine & 182.0810 & $\mathrm{M}+\mathrm{H}$ & $189283.992 \pm 37488.177$ & $98210.812 \pm 27956.879$ & 0.087 \\
\hline \multicolumn{6}{|l|}{ Tryptophan metabolism } \\
\hline Tryptophan & 205.0969 & $\mathrm{M}+\mathrm{H}$ & $1019420.962 \pm 147828.090$ & $645464.129 \pm 213771.769$ & 0.188 \\
\hline Indolepyruvate & 204.0643 & $\mathrm{M}+\mathrm{H}$ & $1947.036 \pm 168.859$ & $66304.072 \pm 28804.879$ & 0.095 \\
\hline Kynurenic acid & 190.0501 & $\mathrm{M}+\mathrm{H}$ & $31028.104 \pm 16880.597$ & $23194.91 \pm 2871.946$ & 0.660 \\
\hline N-Acetylisatin & 190.0501 & $\mathrm{M}+\mathrm{H}$ & $31028.104 \pm 16880.597$ & $23194.91 \pm 2871.946$ & 0.660 \\
\hline Indolepyruvate/Tryptophan ratio & - & $\mathrm{M}+\mathrm{H}$ & $0.00168 \pm 0.000133$ & $0.180 \pm 0.0907$ & 0.095 \\
\hline Kynurenic acid/Tryptophan ratio & - & $\mathrm{M}+\mathrm{H}$ & $0.0338 \pm 0.0223$ & $0.0717 \pm 0.0282$ & 0.322 \\
\hline N-Acetylisatin/Tryptophan ratio & - & $\mathrm{M}+\mathrm{H}$ & $0.0338 \pm 0.0223$ & $0.0717 \pm 0.0282$ & 0.322 \\
\hline \multicolumn{6}{|l|}{ Linoleic acid metabolism } \\
\hline Y-Linolenate & 279.2325 & $\mathrm{M}+\mathrm{H}$ & $26377.484 \pm 10676.857$ & $99976.905 \pm 29811.562$ & 0.049 \\
\hline Crepenynate & 279.2325 & $\mathrm{M}+\mathrm{H}$ & $26377.484 \pm 10676.857$ & $99976.905 \pm 29811.562$ & 0.049 \\
\hline 9-OxOODE & 295.2274 & $\mathrm{M}+\mathrm{H}$ & $174688.392 \pm 46316.891$ & $227818.573 \pm 42553.150$ & 0.423 \\
\hline 13-OxOODE & 295.2274 & $\mathrm{M}+\mathrm{H}$ & $174688.392 \pm 46316.891$ & $227818.573 \pm 42553.150$ & 0.423 \\
\hline \multicolumn{6}{|l|}{$\alpha$-Linolenic acid metabolism } \\
\hline$\alpha$-Linolenic acid & 279.2325 & $\mathrm{M}+\mathrm{H}$ & $26377.484 \pm 10676.857$ & $99976.905 \pm 29811.562$ & 0.049 \\
\hline 13(S)-HpOTrE & 311.2223 & $\mathrm{M}+\mathrm{H}$ & $84042.802 \pm 22155.600$ & $325147.659 \pm 66906.121$ & 0.009 \\
\hline 12,13EOTrE & 293.2113 & $\mathrm{M}+\mathrm{H}$ & $63114.041 \pm 21272.621$ & $143606.124 \pm 19669.706$ & 0.024 \\
\hline 12-OPDA & 293.2113 & $\mathrm{M}+\mathrm{H}$ & $63114.041 \pm 21272.621$ & $143606.124 \pm 19669.706$ & 0.024 \\
\hline OPC8 & 295.2274 & $\mathrm{M}+\mathrm{H}$ & $174688.392 \pm 46316.891$ & $227818.573 \pm 42553.150$ & 0.423 \\
\hline 13(S)-HpOTrE/a-Linolenic acid & - & $\mathrm{M}+\mathrm{H}$ & $19.384 \pm 11.852$ & $4.658 \pm 1.519$ & 0.253 \\
\hline 12,13-EOTrE/ $\alpha$-Linolenic acid & - & $\mathrm{M}+\mathrm{H}$ & $6.821 \pm 2.759$ & $2.142 \pm 0.706$ & 0.139 \\
\hline 12-OPDA/ $\alpha$-Linolenic acid & - & $\mathrm{M}+\mathrm{H}$ & $6.821 \pm 2.759$ & $2.142 \pm 0.706$ & 0.139 \\
\hline OPC8/ $\alpha$-Linolenic acid & - & $\mathrm{M}+\mathrm{H}$ & $73.522 \pm 42.879$ & $3.742 \pm 1.951$ & 0.143 \\
\hline
\end{tabular}


Figure 1
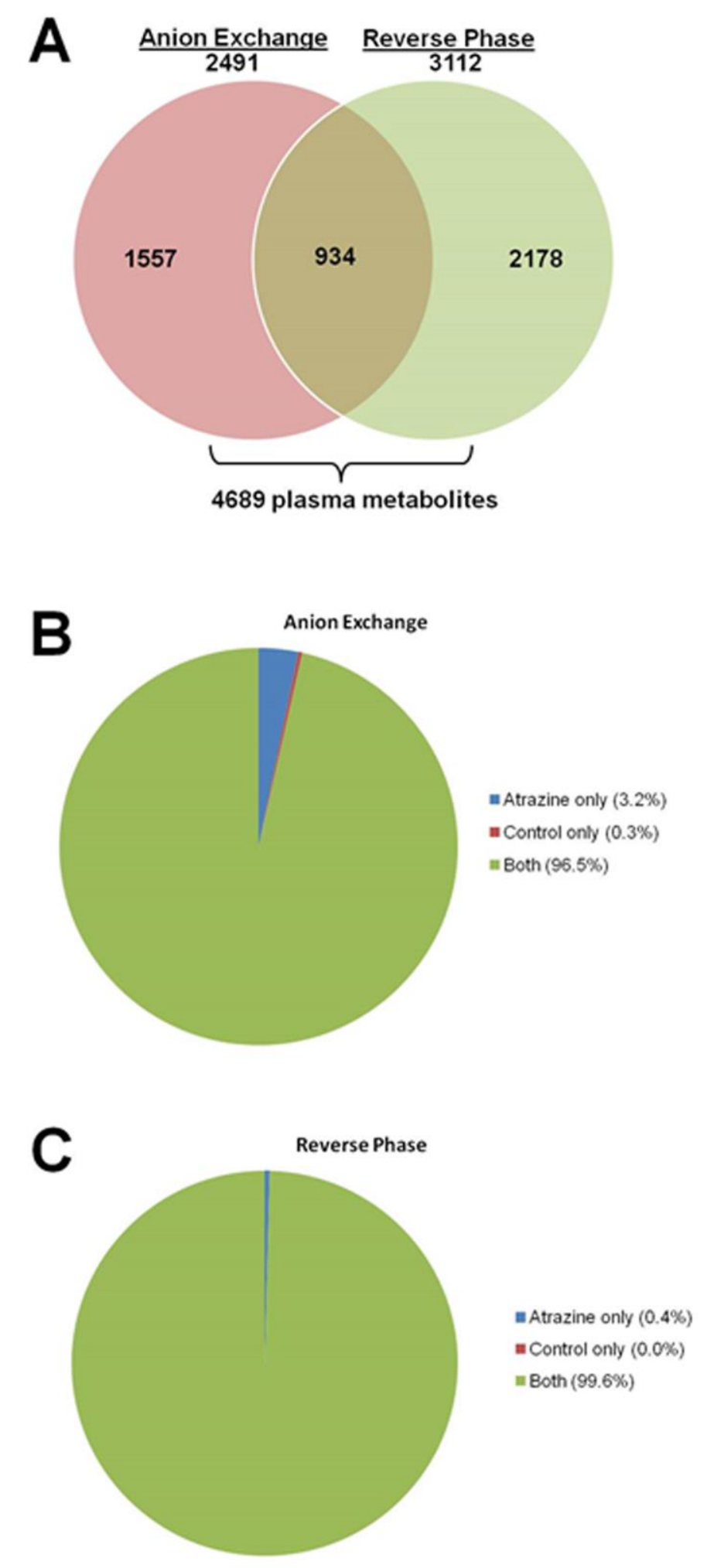
Figure 2

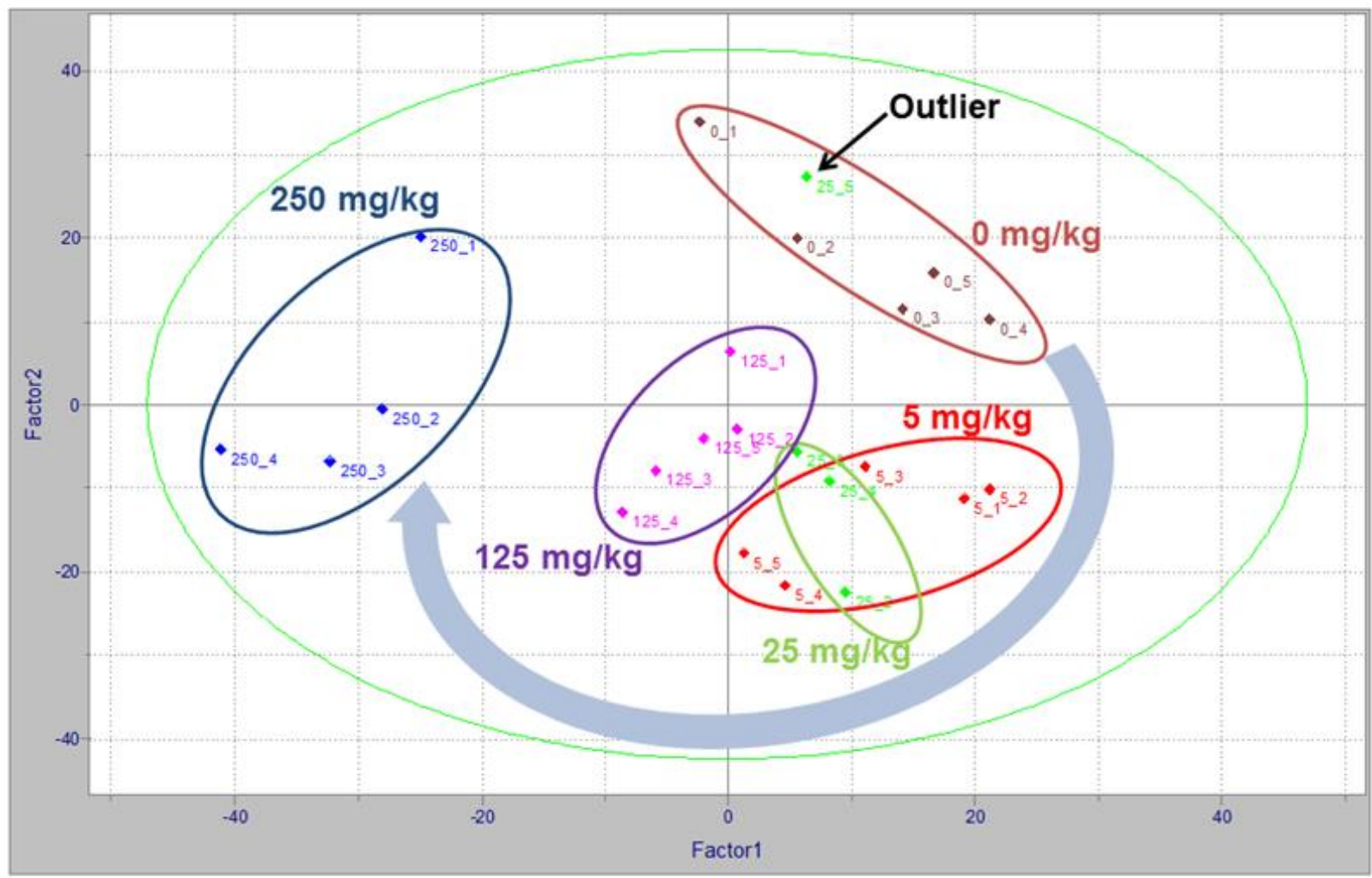


Figure 3

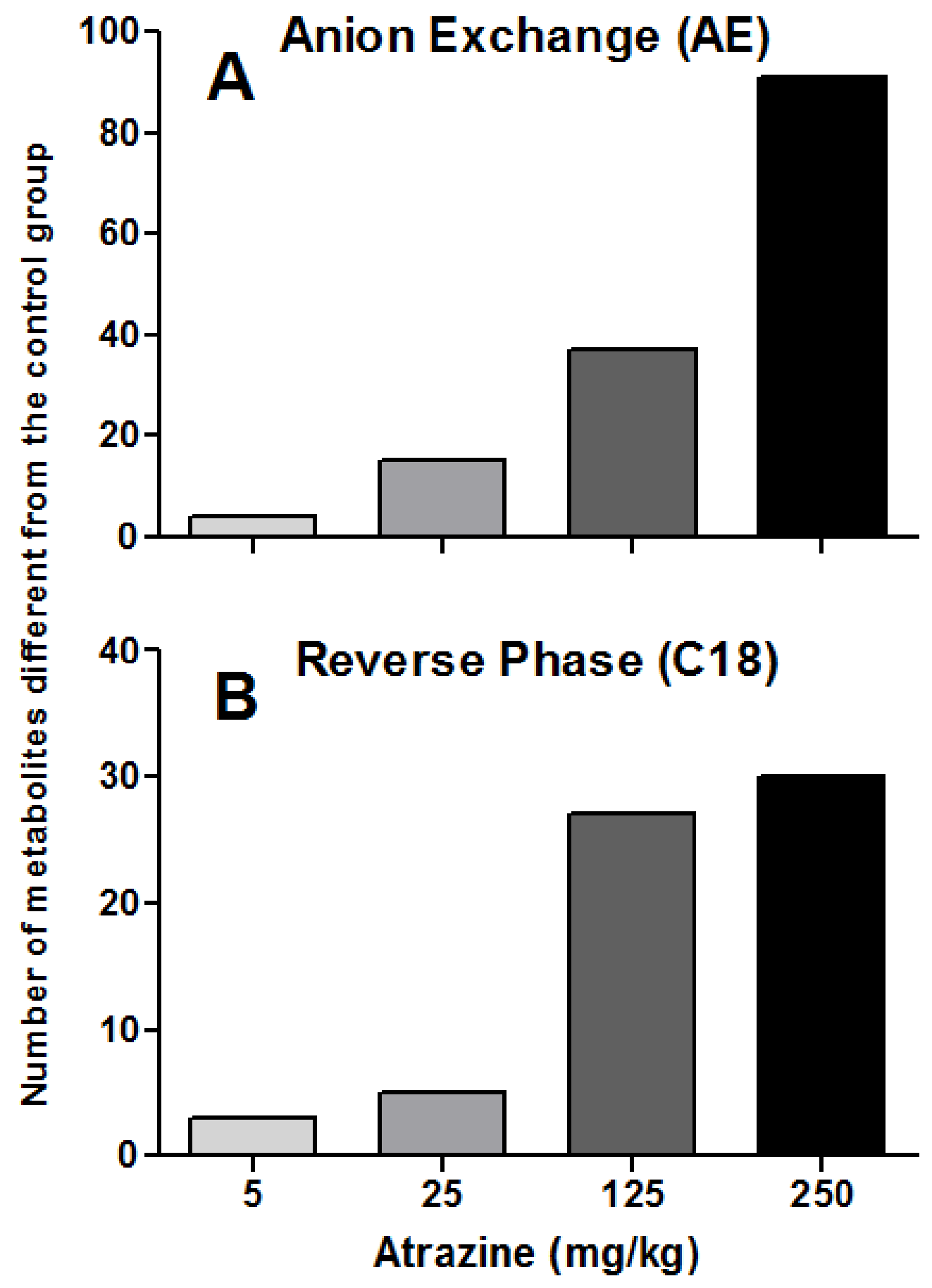


Figure 4
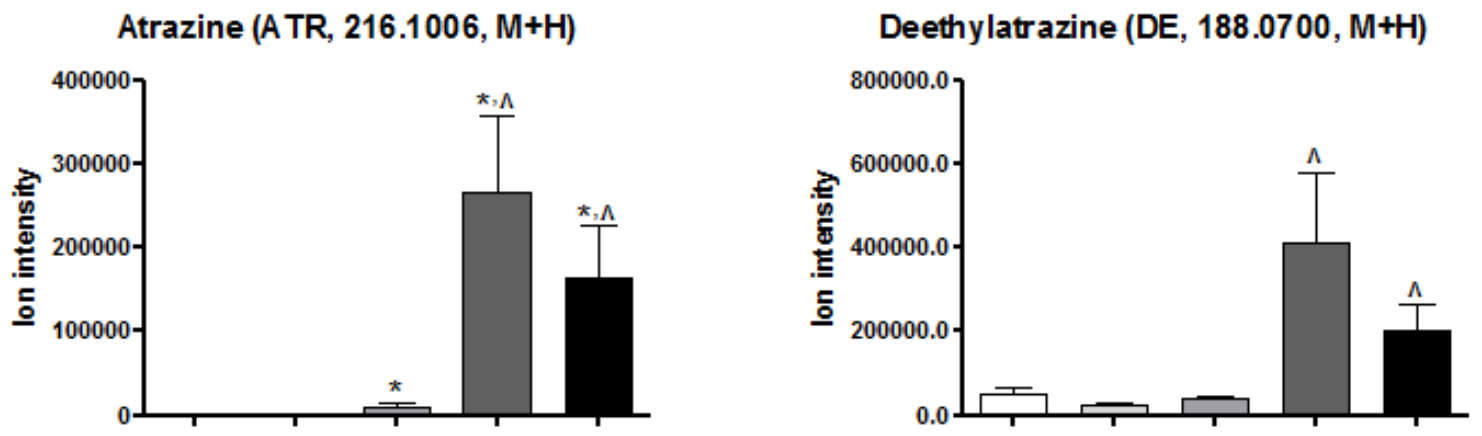

Deisopropylatrazine (DIP, 174.0536, M+H)

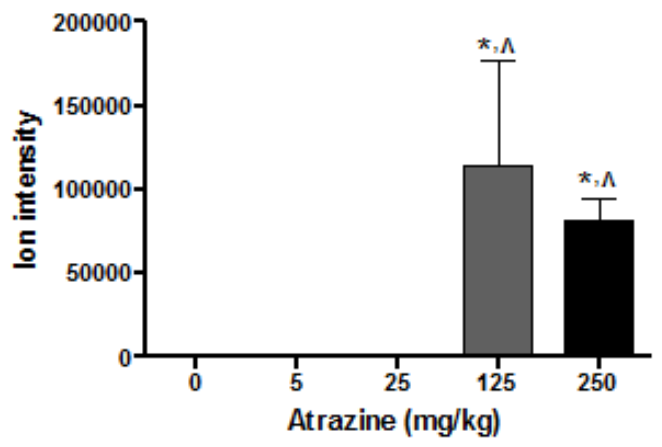

Didealky latrazine (DACT, 146.0226, $\mathrm{M}+\mathrm{H}$ )

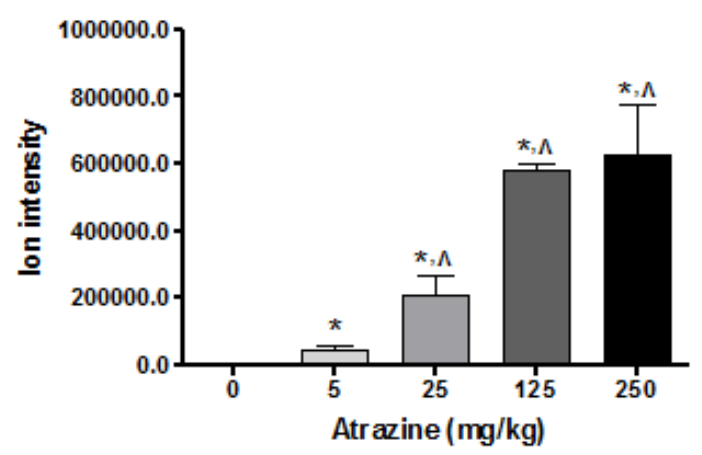


Figure 5

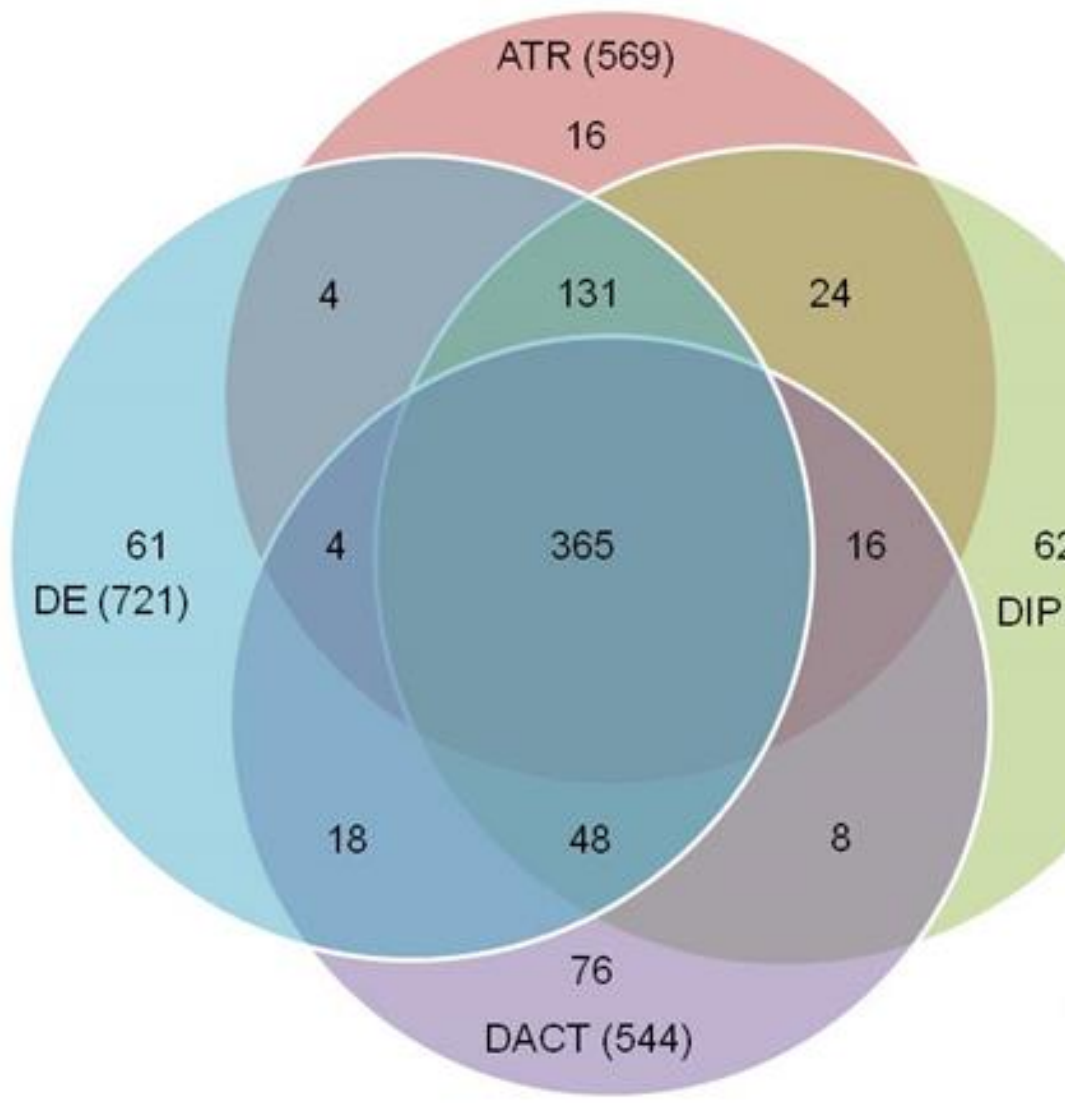

Reverse Phase

62

DIP (744)

ATR: 569

DE: 721

DIP: 744

DACT: 544

ATR+DACT: 394

$A T R+D E+D I P+D A C T: 365$

ATR, DE, DIP, or DACT: 932

Total metabolites: 3112 
Figure 6

A. Tyrosine metabolism pathway (map00350)

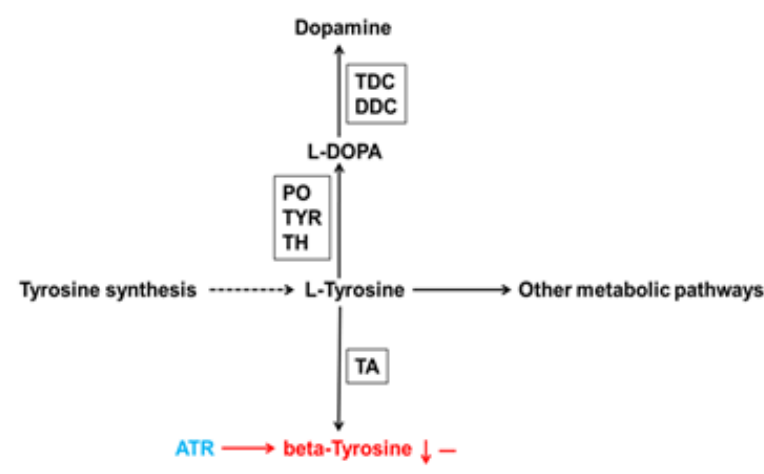

C. Linoleic acid metabolism pathway (map00591)

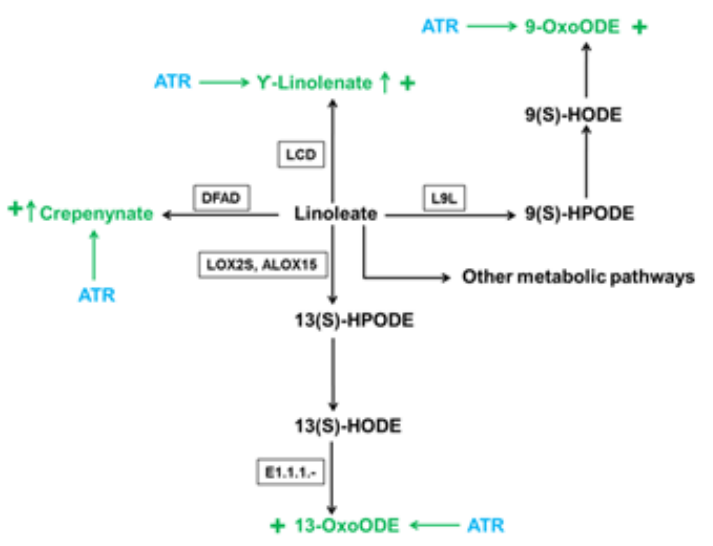

B. Tryptophan metabolism pathway (map00380)

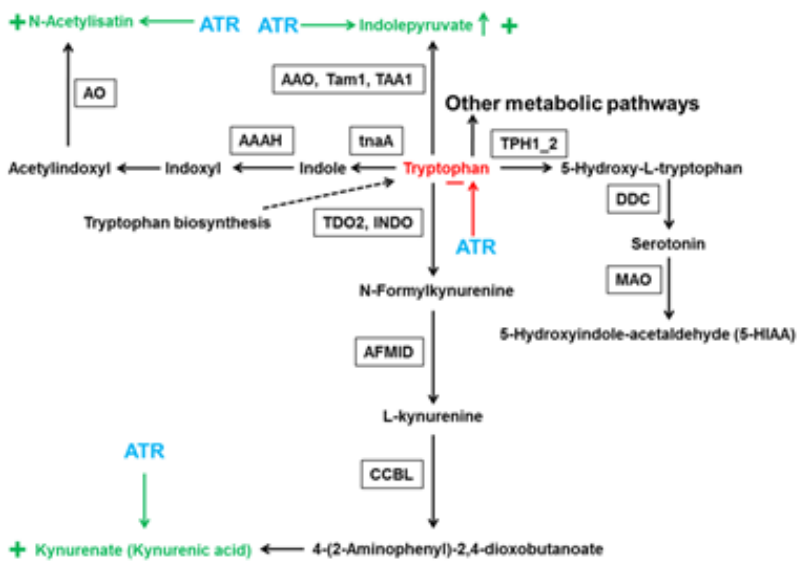

D. alpha-Linolenic acid metabolism pathway (map00592)

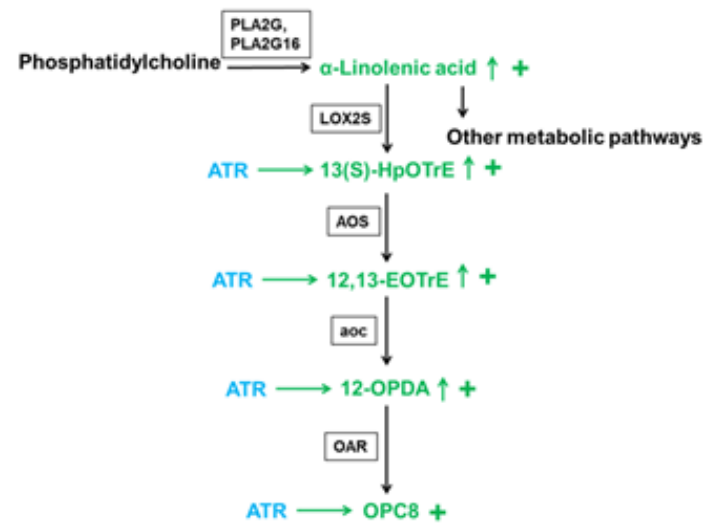

